Special Section: Remote Sensing for Vadose Zone Hydrology

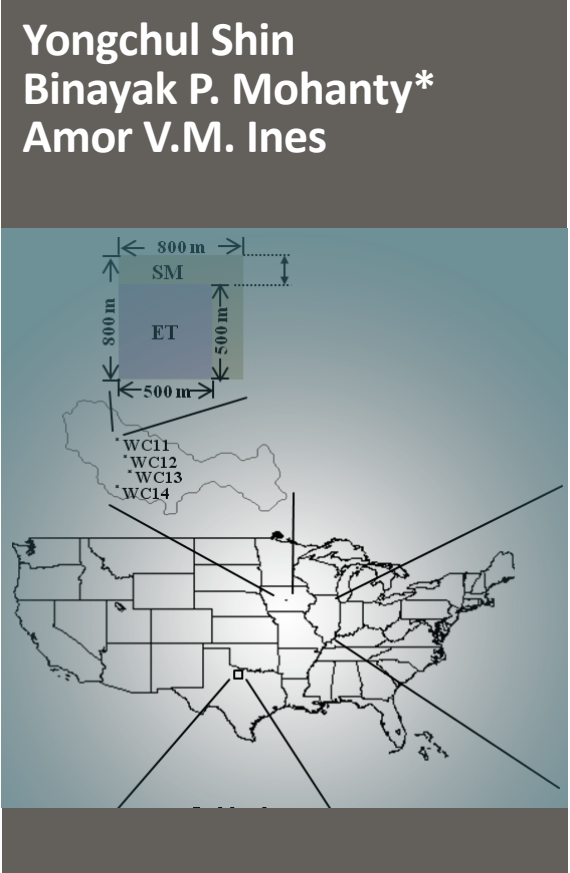

We developed an improved data assimilation scheme for estimating effective soil hydraulic parameters at the remote sensing footprint scale by linking remotely sensed soil moisture and evapotranspiration (ET) time series. Inclusion of ET (multiobjective) in the optimization algorithm reduced the uncertainty in the estimated soil hydraulic parameters in comparison to the objective based on soil moisture only.

Y. Shin, B.P. Mohanty, and A.V.M. Ines, Dep. of Biological and Agricultural Engineering, Texas A\&M Univ., 2117 TAMU, 201 Scoates Hall, College Station, TX 77843; A.V.M. Ines now at International Research Institute for Climate and Society, Earth Institute, Columbia Univ., Palisades, NY 10964. *Corresponding author (bmohanty@tamu.edu).

Vadose Zone J.

doi:10.2136/vzj2012.0094

Received 27 June 2012.

(C) Soil Science Society of America

5585 Guilford Rd., Madison, WI 53711 USA. All rights reserved. No part of this periodical may be reproduced or transmitted in any form or by any means, electronic or mechanical, including photocopying, recording, or any information storage and retrieval system, without permission in writing from the publisher.

\section{Estimating Effective Soil Hydraulic Properties Using Spatially Distributed Soil Moisture and Evapotranspiration}

With the development of many earth-observing remote sensing (RS) platforms, spatially distributed remote sensing products are becoming critical inputs to many hydrologic and meteorological models. Remotely sensed soil moisture (SM) and evapotranspiration (ET) including ground-based data have the potential to be used for estimating pixel-scale soil hydraulic parameters. However, only a few studies have been conducted to better understand the impact of assimilating both SM and ET in estimating soil hydraulic properties of the root zone. In this study, we used inverse modeling based on the Noisy Monte Carlo Genetic Algorithm by linking RS SM and ET derived from the Surface Energy Balance Algorithm for Land for estimating pixel-scale effective soil hydraulic properties. Walnut Creek (lowa), Brown (Illinois), and Lubbock (Texas) test sites were selected to assess the performance of this approach from point to satellite scales using synthetic and validation experiments. For comparison purposes, inverse modeling results were analyzed under three scenarios (ET only, SM only, and SM + ET in the optimization criteria). These results showed that considering both SM and ET components improved the estimations of effective soil hydraulic properties and reduced their uncertainties better than SM or ET only. Overall, although uncertainty exists, our proposed SM + ET based scheme performed well in estimating effective soil hydraulic properties at multiple spatial scales (point, airborne, and satellite footprints) under various hydroclimatic conditions.

Abbreviations: AMSR-E, Advanced Microwave Scanning Radiometer-Earth Observing System; ASTER, Advanced Spaceborne Thermal Emission and Reflection; DOY, Day of the Year; EC, eddy covariance; ET, evapotranspiration; GW, groundwater; MODIS, Moderate Resolution Imaging Spectroradiometer; NMCGA, Noisy Monte Carlo Genetic Algorithm; PSR, Polarimetric Scanning Radiometer; RS, remote sensing; SEBAL, Surface Energy Balance Algorithm for Land; SM, soil moisture; S-SEBI, simplified Surface Energy Balance Index; SWAP, Soil-Water-Atmosphere-Plant; WC, Walnut Creek.

Soil hydraulic properties play a key role in many hydroclimatic processes in the critical zone and land-atmosphere interface (Hanson et al., 1999; Mohanty et al., 2002; Mohanty and Zhu, 2007). They are the limits of the hydraulic behavior of the soil system (e.g., Wood, 1994; Vrugt et al., 2003; Jana and Mohanty, 2012a, 2012b, 2012c).

Root zone SM and ET play complementary roles for water balance in the vadose zone (Xevi et al., 1996). Precipitation returns to the atmosphere as evapotranspiration. More than half of ET losses can be accounted for by soil evaporation and less from plant transpiration in many semiarid regions (Huxman et al., 2005). According to some studies, only soils in the near surface soil layer $(20 \mathrm{~cm}$ from the land surface) contribute to evaporation (Boulet et al., 1997; van Keulen and Hillel, 1974; Yamanaka and Yonetani, 1999). However, soil water is the source of water for transpiration along the entire root zone. Because different crops have different root activities (i.e., root density and distribution) (Breshears et al., 1997; Cable, 1969; Schenk and Jackson, 2002), the transpiration dependence throughout the soil depth could be varied, indicating that ET significantly influences the water cycle at the near surface and in the root zone (Pollacco and Mohanty, 2012).

In general, laboratory methods are used to determine the soil hydraulic functions by direct measurement using soil core samples extracted from the field. The major concern with regard to this traditional method is whether the soil parameters derived by a centimeterscale soil core sample with predefined boundary conditions can represent field-and regional-scale features (Kool and Parker, 1988; van Dam, 2000, Das et al., 2008, 2010). Evapotranspiration can also be measured by eddy covariance methods (Dyer, 1961; Tanner and Greene, 1989) at local scales. With the increasing availability of RS platforms 
characterized by large spatial and temporal coverage, inverse modeling could be explored for estimating spatially distributed effective soil hydraulic properties (Yeh, 1989; Ines and Mohanty, 2008a, 2008b, 2009). To estimate spatially distributed ET, several spatially distributed pixel-based RS schemes-the Surface Energy Balance Algorithm for Land (SEBAL; Bastiaanssen et al., 1998, 2005), Mapping Evapotranspiration at High Resolution and with Internalized Calibration (METRIC; Allen et al., 2007), simplified Surface Energy Balance Index (S-SEBI; Roerink et al., 2000), and Surface Heat Budget of the Arctic Ocean (SHEBA; Su, 2002) have been developed. Ines and Mohanty (2008a) developed an inverse modeling of SM and ET to derive effective soil parameters in a one-dimensional soil water flow model for homogeneous and heterogeneous soil profiles. Although their synthetic experiments were very successful, field-based studies are needed to validate their hypothesis and methods.

The unsaturated zone is quite heterogeneous; thus estimating exact soil parameter values for each point in the field has been deemed unrealistic. Effective soil hydraulic parameters that represent a soil profile can be an alternative. Optimization approaches that use time series of observable data to estimate such properties include Generalized Likelihood Uncertainty Estimation (GLUE) (Beven and Binley, 1992; Beven and Freer, 2001), genetic algorithms (GAs) (Wang, 1991; Ines and Droogers, 2002a; Ines and Mohanty, 2008a, 2008b, 2009), Shuffled Complex Evolution-University of Arizona (SCE-UA) (Duan et al., 1992), and artificial neural networks (ANNs) (Pachepsky et al., 1996; Schaap and Bouten, 1996; Schaap and Leij, 1998; Schaap et al., 1998; Sharma et al., 2006, Jana et al.,2007). Recently, Ines and Mohanty (2008b) developed a Noisy Monte Carlo Genetic Algorithm (NMCGA) for estimating effective soil hydraulic properties. The NMCGA characterizes the first and second moments of the soil hydraulic properties, which can then be used to sample ensembles of soil hydraulic properties describing the soil system.

This study aimed (i) to link NMCGA with SEBAL to integrate pixel-scale SM and ET in the estimation of pixel-scale effective soil hydraulic properties, (ii) to analyze the impacts of using SM, ET, and SM + ET in the optimization criteria for soil hydraulic parameter estimations under different wetness conditions, and (iii) to evaluate the robustness of this approach at different spatial scales ranging from point, to airborne, to satellite sensing.

\section{Materials and Methods Linked Data Assimilation Algorithm}

In this study, we explored an improved inversion modeling approach to estimate van Genuchten (1980) soil hydraulic properties (shape parameters $\alpha$ and $n$, residual and saturated soil moisture $\theta_{\text {res }}$ and $\theta_{\text {sat }}$, and saturated hydraulic conductivity $K_{\text {sat }}$ ) using RS SM and ET products at multiple scales. This inversion approach adapts a soil moisture data assimilation scheme (Ines and Mohanty, 2008a; Shin et al., 2012). Figure 1 shows the framework

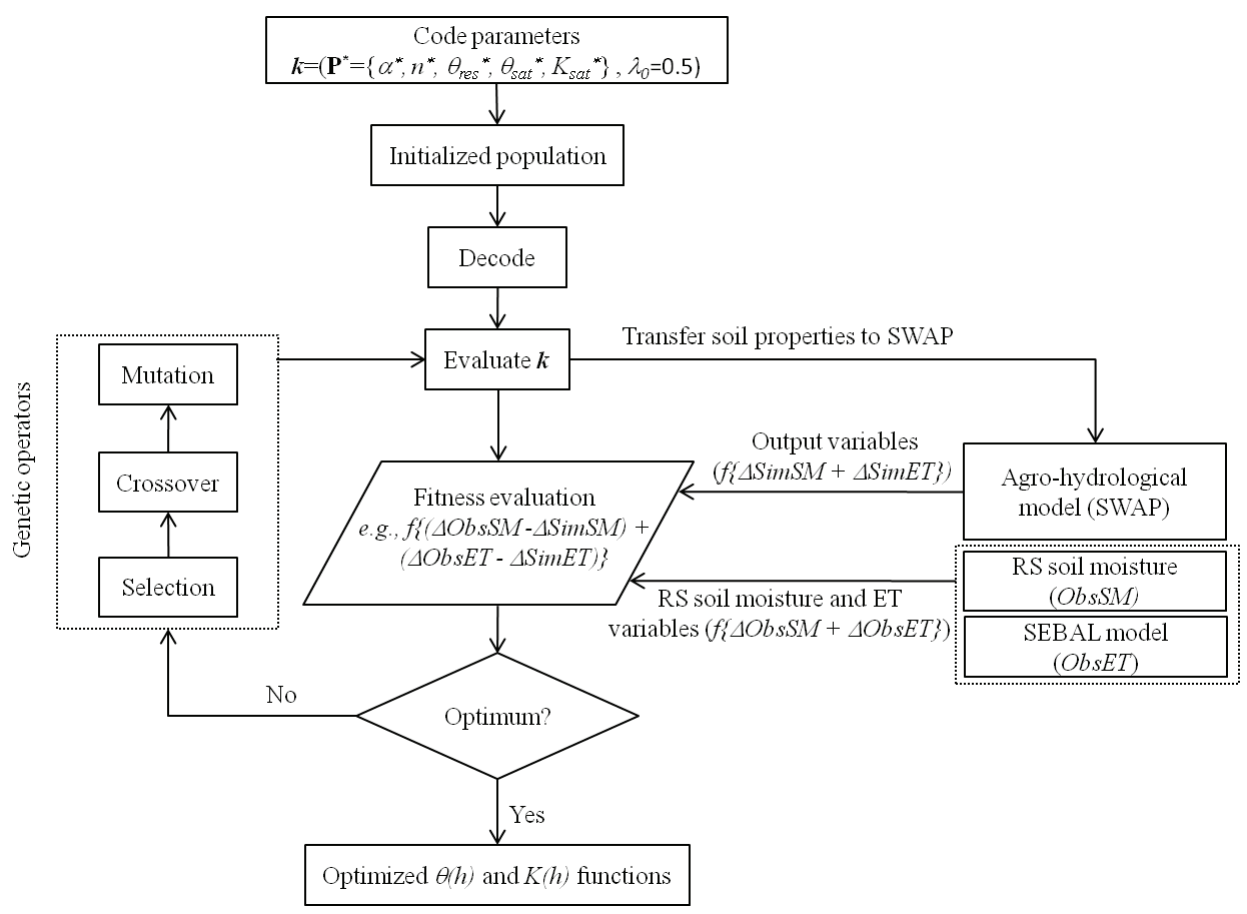

Fig. 1. Framework of the linked Noisy Monte Carlo Genetic Algorithm (NMCGA) and Surface Energy Balance Algorithm for Land (SEBAL) used in this study (ObsSM/ObsET, observed soil moisture/evapotranspiration; SimSM/SimET, simulated soil moisture/evapotranspiration; $\theta(b)$, water retention curve; $K(b)$, hydraulic conductivity; RS, remote sensing; SWAP, Soil-Water-Atmosphere-Plant model; SEBAL, Surface Energy Balance Algorithm for Land model). 
of the linked NMCGA and SEBAL based near-surface SM and ET data assimilation scheme. We can define this approach as the linked NMCGA and SEBAL algorithm that determines the soil water content $[\theta(b)]$ and hydraulic conductivity $[K(b)]$ functions in the soil profile using RS near-surface $(0-1$ or $0-5 \mathrm{~cm}) \mathrm{SM}$ and ET estimates based on a simulation-optimization approach. This data assimilation scheme repeatedly runs a hydrologic model (Soil-Water-Atmosphere-Plant, SWAP) until the derived solutions (soil hydraulic properties) have converged (Abbaspour et al., 1997; Kool and Parker, 1988; Ines and Droogers, 2002a, 2002b). Our suggested approach that considers both the SM and ET components could improve soil parameter estimations across the land surface and in the root zone.

\section{Hydrologic Model}

The SWAP model is a one-dimensional physically based model for simulating water flow across the soil, water, atmosphere, and plant system (Kroes et al., 1999; van Dam et al., 1997). In the SWAP model, water flow is modeled using the Richards equation. The soil hydraulic functions in the soil column can be described by the analytical expressions of van Genuchten (1980) and Mualem (1976) using the relationship between the soil water content $(\theta)$, pressure head $(b)$, and unsaturated hydraulic conductivity $(K)$ :

$$
\frac{\partial \theta}{\partial t}=C(b) \frac{\partial b}{\partial t}=\frac{\partial[K(b)(\partial h / \partial z+1)]}{\partial z}-S(b)
$$

where $\theta$ is the volumetric water content $\left(\mathrm{cm}^{3} \mathrm{~cm}^{-3}\right), K$ is the hydraulic conductivity $\left(\mathrm{cm} \mathrm{d}^{-1}\right), h$ is the soil water pressure head $(-\mathrm{cm}), z$ is the vertical soil depth $(\mathrm{cm})$ taken positive upward, $t$ is the time (d), $C$ is the differential soil water capacity $\left(\mathrm{cm}^{-1}\right)$, and $S(b)$ is the actual soil water extraction rate by plants $\left(\mathrm{cm}^{3} \mathrm{~cm}^{-3}\right.$ $\mathrm{d}^{-1}$ ) defined as

$$
S(b)=\alpha_{\mathrm{w}}(b) \frac{T_{\mathrm{pot}}}{Z_{\mathrm{r}}}
$$

where $T_{\text {pot }}$ is the potential transpiration $\left(\mathrm{cm} \mathrm{d}^{-1}\right), Z_{\mathrm{r}}$ is the rooting depth $(\mathrm{cm})$, and $\alpha_{w}$ is a reduction factor as a function of $h$ and accounts for water deficit and $\mathrm{O}_{2}$ stress (Feddes et al., 1978). The Richards Eq. [1], using the finite difference scheme described by Belmans et al. (1983), allows the use of soil hydraulic databases and all kinds of management scenarios:

$$
\begin{aligned}
& S_{\mathrm{e}}=\frac{\theta(b)-\theta_{\text {res }}}{\theta_{\text {sat }}-\theta_{\text {res }}}=\left(\frac{1}{1+|\alpha h|^{n}}\right)^{m} \\
& K(b)=K_{\text {sat }} S_{\mathrm{e}}^{\lambda}\left[1-\left(1-S_{\mathrm{e}}^{1 / m}\right)^{m}\right]^{2}
\end{aligned}
$$

where $S_{\mathrm{e}}$ is the relative saturation (dimensionless), $\theta_{\text {res }}$ is the residual water content $\left(\mathrm{cm}^{3} \mathrm{~cm}^{-3}\right)$ in the dry range, and $\theta_{\text {sat }}$ is the saturated water content $\left(\mathrm{cm}^{3} \mathrm{~cm}^{-3}\right), \alpha, n, m$, and $\lambda$ are shape parameters, $K_{\text {sat }}$ is the saturated hydraulic conductivity $\left(\mathrm{cm} \mathrm{d}^{-1}\right)$, and $m=1-1 / n$.

Various conditions for the top (atmospheric) and bottom boundaries (free drainage condition and groundwater table depths) can be simulated by the SWAP model (van Dam et al., 1997). The SWAP model contains simple and detailed crop growth routines. These models, combined with water management modules (e.g., irrigation and drainage) (van Dam et al., 1997; van Dam, 2000), simulate the impacts of climate, soil texture, plant type, and crop water management. Using the Penman-Monteith equation, the SWAP model calculates not only the potential and actual soil evaporation but also potential and actual plant transpiration partitioned by the leaf area index or soil cover fraction of the land unit. This model performs well under various climatic and environmental conditions (Wesseling and Kroes, 1998; Sarwar et al., 2000; Droogers et al., 2000; Singh et al., 2006a, 2006b).

\section{Surface Energy Balance Algorithm for Land Model}

Evapotranspiration across the land-atmosphere boundary is generated by water loss from open water, the soil, and the plant surface and is governed by energy and heat exchanges at the land surface. The computation of ET by the SEBAL model includes three steps: (i) preliminary processing of RS data (producing the normalized difference vegetation index, albedo, and temperature images), (ii) selection of the hot and cold pixels (a hot pixel assumes that all the energy is used to heat the surface and a cold pixel assumes that all the energy is used to evaporate water), and (iii) estimation of pixel-based ET (Daroonwan et al., 2008). The key input data sets for the SEBAL model consist of spectral radiances in the visible, near-infrared, and thermalinfrared wavelengths from Moderate Resolution Imaging Spectroradiometer (MODIS) surface reflectance products (i.e., solar zenith angle, quality control band, land surface temperature, and band emissivities 31 and 32), weather data (wind speed), and regional information (i.e., height of vegetation, altitude of target area, and specific locations of hot and cold pixels). Evapotranspiration is related to the surface-energy balance:

$R_{\mathrm{n}}=G_{0}+H+\mathrm{LE}$

where $R_{\mathrm{n}}\left(\mathrm{W} \mathrm{m}{ }^{-2}\right)$ is the net radiation absorbed at the land surface, $G_{0}\left(\mathrm{~W} \mathrm{~m}^{-2}\right)$ is the soil heat flux, $H\left(\mathrm{~W} \mathrm{~m}^{-2}\right)$ is the sensible heat flux, and LE $\left(\mathrm{W} \mathrm{m}^{-2}\right)$ is the latent heat flux associated with ET.

\section{Genetic Algorithm Implementation}

Genetic algorithms (GAs), based on the theory of "survival of the fittest" by Charles Darwin (Holland, 1975; Goldberg, 1989), are powerful search algorithms for optimal solutions from unknown variable spaces. Basically, GAs create the chromosome, which contains the variable information, using a "string" structure of binary digits (i.e., 0 and 1). These binary strings recursively compete 
to survive in the mating pool to produce the next generation through the GA operations of selection, crossover, and mutation:

1. Selection: In the selection process, the strongest chromosome competes against others and survives to be selected. The rest of them die (are discarded).

2. Crossover: The surviving binary chromosomes then exchange their genetic information through mating during the crossover to produce their offspring.

3. Mutation: The freshly selected chromosomes are mutated to generate new genetic materials for the next generation. Finally, the mutated chromosomes are restored instead of certain genetic characteristics being lost by degeneration.

Genetic algorithms are very flexible to apply to different problems such as for estimating uncertainty envelopes of risk management options (Wu et al., 2006); these GAs are the so-called noisy GAs. Noisy genetic algorithms operated in a noisy environment have been suggested for the fitness evaluation of chromosome variables subjected to a stochastic field (Miller and Goldberg, 1996; Wu et al., 2006). Ines and Mohanty (2008b) integrated a NGA with a resampling algorithm (ensemble: $e$ ) for the Monte Carlo (MC) simulation (Efron, 1982; Miller and Goldberg, 1996), the NMCGA, to determine the fittest chromosomes (the effective soil hydraulic parameter sets, $\left.\mathbf{P}=\left\{\alpha, n, \theta_{\text {res }}, \theta_{\text {sat }}, K_{\text {sat }}\right\}\right)$. The input parameter sets for the hydrologic model can be shown as $\mathbf{k}=\left\{\mathbf{P}, \lambda_{0}\right\}$. The shape parameter of lamda $\left(\lambda_{0}=0.5\right)$ is fixed in modeling. We transferred the parameter set $(\mathbf{P})$ as the parameter set $\left(\mathbf{P}^{*}=\left\{\alpha^{*}, n^{*}, \theta_{\text {res }}{ }^{*}, \theta_{\text {sat }}{ }^{*}, K_{\text {sat }}{ }^{*}\right\}\right)$ to consider uncertainties (e.g., representing the heterogeneity of the land surface in a RS product) of individual soil parameters in modeling. Thus, the set $\mathbf{k}=\left\{\mathbf{P}^{*}, \lambda_{0}\right\}$ is used in this approach. In the NMCGA, the GA estimates the combinations of parameter statistics $\left(\mathbf{P}^{*}\right)$ :

$$
\mathbf{P}^{*}=\left\{\mu_{(\alpha)}, \sigma_{(\alpha)}^{2}, \mu_{(n)}, \sigma_{(n)}^{2}, \mu_{\left(\theta_{\text {res }}\right)}, \sigma_{\left(\theta_{\text {res }}\right)}^{2}, \mu_{\left(\theta_{\text {sat }}\right)}, \sigma_{\left(\theta_{\text {sat }}\right)}^{2}, \mu_{\left(K_{\text {sat }}\right)}, \sigma_{(K \text { sat })}^{2}\right\}
$$

Note that $\mathbf{P}^{*}$ is the statistics ( $\mu$ are means and $\sigma$ are standard deviations) of individual effective soil hydraulic parameters, The MC algorithm then derives the realizations $(r)$ of parameter combinations based on statistics. The noisy fitness of the parameter combinations for all the realizations derived by the MC simulation in one resampling event is estimated along the given generations.

In this study, the NMCGA was linked with the SEBAL model to consider not only soil moisture but also ET in estimating the soil parameters. The linked NMCGA and SEBAL algorithm estimates the effective hydraulic parameters by minimizing the difference between the observed (pixel-based) and simulated estimates of both SM and ET time series $(t)$. The representations of the parameter statistics (Eq. [6]) are shown in Table 1. The objective functions for the SM and ET components $\left(\mathrm{OF}_{S M}\right.$ and $\mathrm{OF}_{\mathrm{ET}}$, respectively) are

$$
\begin{gathered}
\mathrm{OF}_{\mathrm{SM}}(\mathbf{k})_{e}=\min \left\{\frac{1}{T} \sum_{t=1}^{T}\left|\frac{1}{N_{\text {resample }}}\right| \sum_{r=1}^{N_{\text {resample }}} \operatorname{SimSM}\left(\mathbf{k}_{r}\right)_{t, e}\right] \\
\left.-\mathrm{ObsSS}_{t} \mid\right\} \forall e \\
\mathrm{OF}_{\mathrm{ET}}(\mathbf{k})_{e}=\min \left\{\frac{1}{T} \sum_{t=1}^{T} \mid \frac{1}{N_{\text {resample }}}\left[\sum_{r=1}^{N_{\text {resample }}} \operatorname{SimET}\left(\mathbf{k}_{r}\right)_{t, e}\right]\right. \\
\left.-\mathrm{ObsET}_{t} \mid\right\} \forall e
\end{gathered}
$$

where $\mathbf{k}_{r}$ is the combinations of effective soil hydraulic parameters $(\mathbf{k})$ with realizations $(r)$ generated by the MC resampling, $e$ is the resampling numbers (or ensembles), $N_{\text {resample }}$ is the number of realizations $(r)$ derived from each resampling event, $\operatorname{SimSM}\left(\mathbf{k}_{r}\right)$ is the simulated soil moisture with $N_{\text {resample }}(r), \operatorname{SimET}\left(\mathbf{k}_{r}\right)$ is the simulated ET with $N_{\text {resample }}(r)$, ObsSM is the observed (pixelbased) soil moisture, ObsET is the observed (pixel-based) ET, $t$ is the time index, and $T$ is the time domain, respectively. All variables

Table 1. Representation of the effective soil hydraulic properties for the linked NMCGA (global search space $=32 \times 32 \times 64 \times 64 \times 128 \times 128 \times 32$ $\left.\times 32 \times 1024 \times 1024=7.3787 \times 10^{19}\right)$ and SEBAL algorithms.

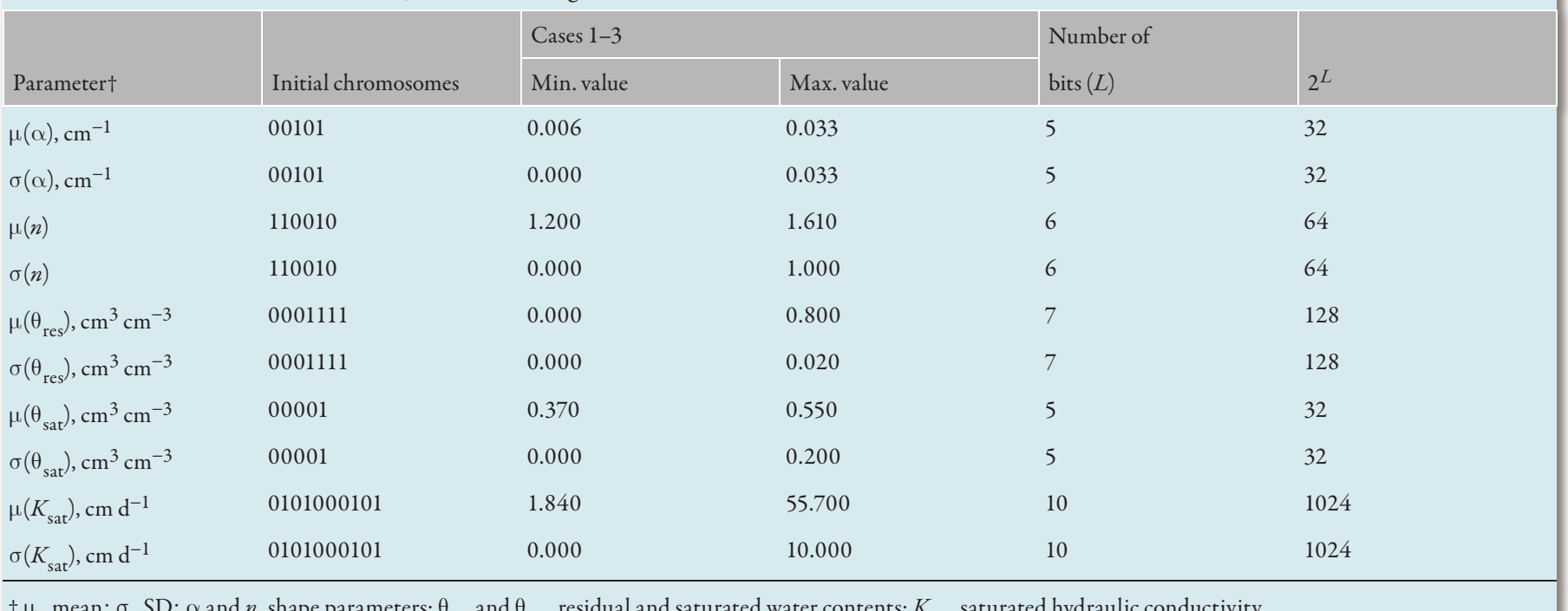

$\dagger \mu$, mean; $\sigma, \mathrm{SD} ; \alpha$ and $n$, shape parameters; $\theta_{\text {res }}$ and $\theta_{\text {sat }}$, residual and saturated water contents; $K_{\text {sat }}$, saturated hydraulic conductivity. 
$\left(\mathrm{SM}, \mathrm{cm}^{3} \mathrm{~cm}^{-3}\right.$ and ET, $\left.\mathrm{mm} \mathrm{d}^{-1}\right)$ were normalized for the objective functions. The optimization is constrained as

$$
\begin{gathered}
\text { ConstrainedSM }(\mathbf{k})_{t, e}= \\
\left\{\begin{array}{c}
+\mathrm{PCI}_{\mathrm{SM}}\left[\operatorname{SimSM}\left(\mathbf{k}_{r}\right)_{t, e}\right]>\mathrm{ObsSM}_{t} \\
-\mathrm{PCI}_{\mathrm{SM}}\left[\operatorname{SimSM}\left(\mathbf{k}_{r}\right)_{t, e}\right]<\mathrm{ObsSM}_{t} \\
(\text { where } t \leq T), \forall e
\end{array}\right.
\end{gathered}
$$

ConstrainedET $(\mathbf{k})_{t, e}=$

$$
\begin{gathered}
\left\{\begin{array}{c}
+\mathrm{PCI}_{\mathrm{ET}}\left[\operatorname{SimET}\left(\mathbf{k}_{r}\right)_{t, e}\right]>\mathrm{ObsET}_{t} \\
-\mathrm{PCI}_{\mathrm{ET}}\left[\operatorname{SimET}\left(\mathbf{k}_{r}\right)_{t, e}\right]<\mathrm{ObsET}_{t}
\end{array}, \forall t\right. \\
(\text { where } t \leq T), \forall e
\end{gathered}
$$

where

$$
\begin{aligned}
& \pm \mathrm{PCI}_{\mathrm{SM}}\left[\operatorname{SimSM}\left(\mathbf{k}_{r}\right)\right]_{t, e}= \\
& \frac{1}{N_{\text {resample }}} \sum_{r=1}^{N_{\text {resample }}} \operatorname{SimSM}\left(\mathbf{k}_{r}\right)_{t, e} \pm \text { PCIfactor }_{\text {SM }}
\end{aligned}
$$

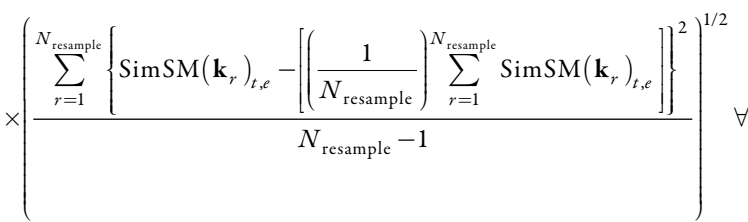

$$
\begin{aligned}
& \text { ( where } t \leq T), \forall e \\
& \pm \mathrm{PCI}_{\mathrm{ET}}\left[\operatorname{SimET}\left(\mathbf{k}_{r}\right)\right]_{t, e}= \\
& \frac{1}{N_{\text {resample }}} \sum_{r=1}^{N_{\text {resample }}} \operatorname{SimET}\left(\mathbf{k}_{r}\right)_{t, e} \pm \text { PCIfactor }_{\mathrm{ET}} \\
& \times\left(\frac{\sum_{r=1}^{N_{\text {resample }}}\left\{\operatorname{SimET}\left(\mathbf{k}_{r}\right)_{t, e}-\left[\left(\frac{1}{N_{\text {resample }}}\right)_{r=1}^{N_{\text {resample }}} \operatorname{SimET}\left(\mathbf{k}_{r}\right)_{t, e}\right]\right\}^{2}}{N_{\text {resample }}-1}\right)^{1 / 2} \forall \\
& \text { (where } t \leq T), \forall e
\end{aligned}
$$

where ConstrainedSM $(\mathbf{k})$ is the logical constraint of SM, Constrained ET $(\mathbf{k})$ is the logical constraint of ET, \pm PCIfactor ${ }_{S M}$ are the $\pm 95 \%$ confidence intervals (PCIs) of SM, and \pm PCIfactor $_{\mathrm{ET}}$ are the \pm 95 PCIs of ET.

The (ensemble) MC-based soil moisture and ET estimates are constrained by the observed SM and ET with \pm PCIfactor $_{S M}$ in Eq. [9] and \pm PCIfactor ${ }_{\mathrm{ET}}$ in Eq. [10]. The modified penalty method (Hilton and Culver, 2000) was used in the objective function $Z(\mathbf{k})$ :

$$
\begin{aligned}
Z(\mathbf{k})_{e}= & f\left[\mathrm{OF}_{\mathrm{SM}}(\mathbf{k})_{e}\right]\left[1+\operatorname{Penalty}_{\mathrm{SM}}(\mathbf{k})_{e}\right] \\
& +(1-f)\left[\mathrm{OF}_{\mathrm{ET}}(\mathbf{k})_{e}\right]\left[1+\text { Penalty }_{\mathrm{ET}}(\mathbf{k})_{e}\right] \\
& \left\{\begin{array}{l}
f=1, \quad \mathrm{SM} \text {-only criterion } \\
f=0, \quad \text { ET-only criterion } \quad \forall e \\
0<f<1, \mathrm{SM}+\mathrm{ET} \text { joint criterion }
\end{array}\right.
\end{aligned}
$$

We then evaluated the fitness of the model outputs:

$$
\text { fitness }\left(\mathbf{P}^{*}\right)_{e}=\frac{1}{Z(\mathbf{k})_{e}} \forall e
$$

The weighting factor $(f)$ was used to assign the different weights to SM and ET in the objective function. The value of $\mathbf{k}_{r}$ is highly subject to a stochastic field, indicating that the fitness $\left(\mathbf{P}^{*}\right)$ is not always similar for each MC resampling event. The noisy fitness is minimized by estimating the so-called sampling fitness [Sfitness $\left.\left(\mathbf{P}^{*}\right)\right]$ (Ines and Mohanty, 2008b) by averaging the fitness $\left(\mathbf{P}^{*}\right)$ of each ensemble $(e)$ from the $\mathrm{MC}$ resampling:

$\operatorname{Sfitness}\left(\mathbf{P}^{*}\right)=\frac{1}{E} \sum_{e=1}^{E}$ fitness $\left(\mathbf{P}^{*}\right)$

where $E$ is the ensemble domain for the MC resampling. The values of Penalty ${ }_{S M}(\mathbf{k})_{e}$ and Penalty ET $(\mathbf{k})_{e}$ in Eq. [13] are determined by the limits of ConstrainedSM $(\mathbf{k})_{t, e}$ of Eq. [9] and ConstrainedET $(\mathbf{k})_{t, e}$ of Eq. [10] and are defined as:

$$
\begin{aligned}
& \operatorname{Penal}_{\mathrm{SM}}(\mathbf{k})_{e, j}= \\
& \sum_{t=1}^{T} \xi_{t, j}\left\{\operatorname{ObsSM}_{t}-\mathrm{PCI}_{\mathrm{SM} j}\left[\operatorname{SimSM}\left(\mathbf{k}_{r}\right)\right]_{t, e}\right\}^{2} \forall e \\
& \operatorname{Penal}_{\mathrm{ET}}(\mathbf{k})_{e, j}= \\
& \sum_{t=1}^{T} \xi_{t, j}\left\{\operatorname{ObsET}_{t}-\mathrm{PCI}_{\mathrm{ET} j}\left[\operatorname{SimET}\left(\mathbf{k}_{r}\right)\right]_{t, e}\right\}^{2} \forall e
\end{aligned}
$$

where $j$ is the penalty coefficient:

$$
\begin{aligned}
& j= \begin{cases}1, & +\mathrm{PCI}_{\mathrm{SM}},+\mathrm{PCI}_{\mathrm{ET}} \\
2, & -\mathrm{PCI}_{\mathrm{SM}},-\mathrm{PCI}_{\mathrm{ET}}\end{cases} \\
& \xi_{t, j}=\left\{\begin{array}{ll}
10, & \text { if FALSE } \\
0, & \text { otherwise }
\end{array} \forall j, \forall t\right.
\end{aligned}
$$

$\operatorname{Penalty}_{\mathrm{SM}}(\mathbf{k})_{e}=\sum_{j=1}^{2} \operatorname{Penal}_{\mathrm{SM}}(\mathbf{k})_{e, j} \forall e$

$\operatorname{Penalty}_{\mathrm{ET}}(\mathbf{k})_{e}=\sum_{j=1}^{2} \operatorname{Penal}_{\mathrm{ET}}(\mathbf{k})_{e, j} \forall e$

\section{Numerical Experiments}

We conducted this study under the assumption that the effective soil hydraulic parameters in the unsaturated zone can be quantified using pixel-based remotely sensed SM (e.g., Polarimetric Scanning Radiometer [PSR], Electronically Scanned Thinned Array Radiometer [ESTAR], Advanced Microwave Scanning Radiometer-Earth Observing System [AMSR-E], etc.) and ET (e.g., MODIS, LANDSAT, Advanced Spaceborne Thermal Emission and Reflection [ASTER], etc.) products. To evaluate the 
NMCGA, several synthetic and field validation experiments were conducted: Case 1, a homogeneous soil column with free drainage; Case 2, a homogeneous soil column with a shallow groundwater (GW) table depth (GW $-100 \mathrm{~cm}$ from the soil surface); and Case 3: field validation experiments under various hydroclimatic conditions in Iowa, Illinois, and Texas. For Cases 1 and 2, the near-surface soil moisture $(0-1 \mathrm{~cm})$ and ET time series as target values were generated by the SWAP model using the available soil hydraulic parameters from the UNSODA database (Leij et al., 1999) in a forward mode. For Case 3, several field sites at Brown, IL, Walnut Creek (WC 11-14), IA, and Lubbock, TX, were selected for the validation studies as shown in Fig. 2. We assumed that the homogeneous soil columns with the free drainage condition can represent arid and semiarid regions, while humid and semihumid regions have shallow GW table levels ( $\mathrm{GW}-100 \mathrm{~cm}$ from the soil surface) as shown in Fig. 3.

\section{Case 1: Homogeneous Soil Column with Free Drainage} We generated the daily (synthetic) SM and ET values using three different soil textures including sandy loam, silt loam, and clay loam under various climate conditions and corn (Zea mays L.) cover in a forward mode as the observations. The SWAP model was simulated during the standard crop growing season (1 May-31 Oct. 2005) in Lubbock, TX, under a rainfed condition. For this study site, the atmospheric forcings are available from the Texas ET

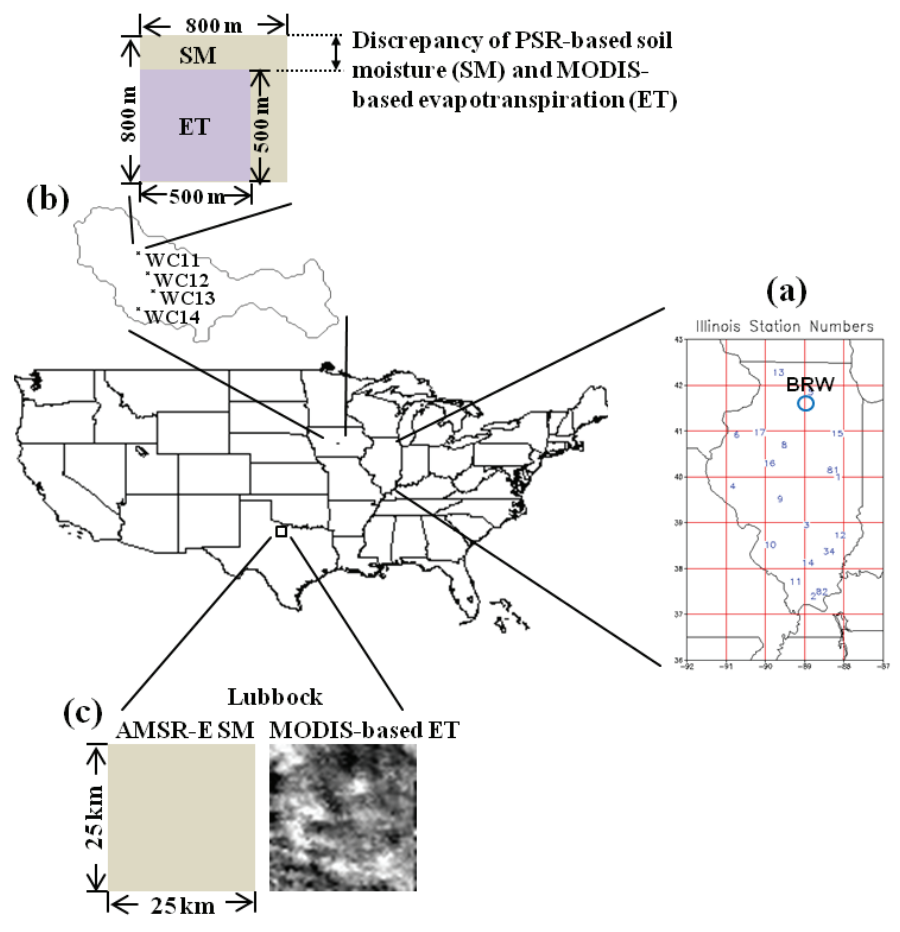

Fig. 2. Study areas: (a) the Brown (BRW) site in Illinois, (b) the Walnut Creek (WC 11-14) sites in Iowa based on Polarimetric Scanning Radiometer (PSR) and Moderate Resolution Imaging Spectroradiometer (MODIS), and (c) the Lubbock site in Texas based on Advanced Microwave Scanning Radiometer-Earth Observing System (AMSR-E) and MODIS. network (http://texaset.tamu.edu/index.php). For these numerical studies (Case 1), it was assumed that the bottom boundary of the soil column is well drained. To evaluate the impact of the ET component in estimating the effective soil hydraulic parameters, three different scenarios were used: (i) the ET-only $(f=0)$ criterion, (ii) the SM-only $(f=1)$ criterion, and (iii) the SM + ET [ $f \mathrm{SM}+$ $(1-f)$ ET: $0<f<1]$ criterion (Ines and Mohanty, 2008a). For the third scenario, we tested various weighting factors $(f=0.1-$ 0.9 ), assigning different weights to SM and ET, and selected the weighting factor of 0.8 , which has a better match (simulation of both SM and ET) with observations.

\section{Case 2: Homogeneous Soil Column with Shallow Groundwater Table}

According to Ines and Mohanty (2008a, 2008b, 2009) and Shin et al. (2012), the effective soil parameter estimations were considerably affected by the presence of shallow groundwater tables (e.g., GW $-100 \mathrm{~cm}$ from the soil surface). The ET component contributing to the water balance in the unsaturated zone was examined in estimating the soil parameters for sandy loam, silt loam, and clay loam soils in the presence of a shallow ground water table at -100 $\mathrm{cm}$. Note that we only considered the shallow ground water table depth of $-100 \mathrm{~cm}$ for Case 2 as the extreme scenario. Case 2 was conducted under the same modeling condition as Case 1.

\section{Case 3: Field Validation Experiments}

Field testing of our proposed inverse modeling based data assimilation algorithm was performed for evaluating the effective soil hydraulic parameter estimation at the point, airborne, and

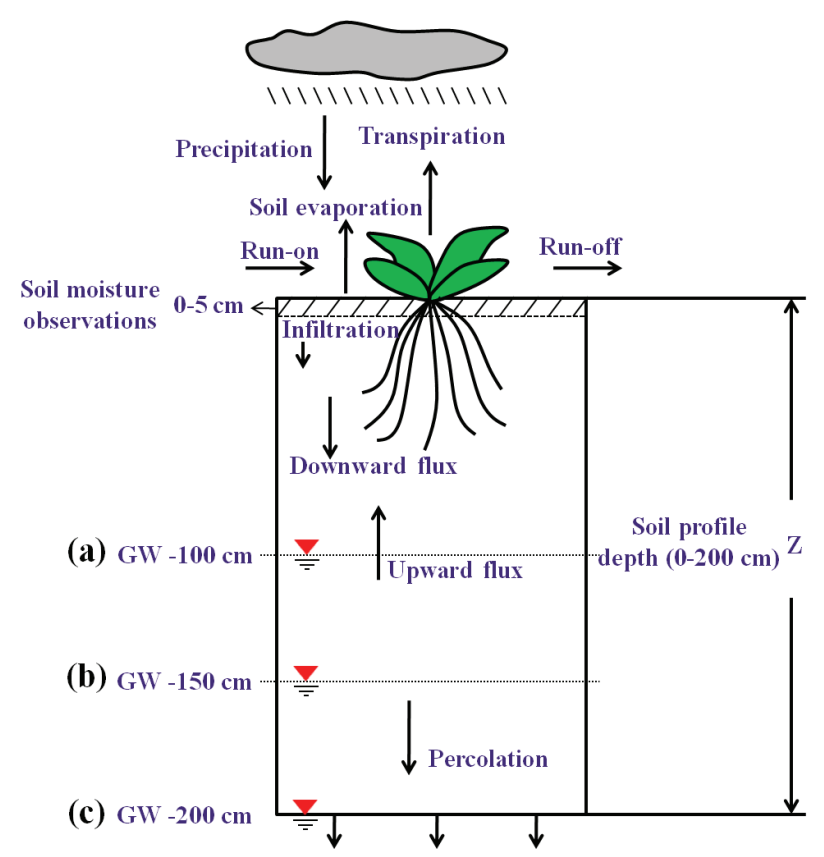

(d) Free drainage

Fig. 3. Homogeneous soil column for numerical experiments under free drainage and shallow groundwater (GW) tables: (a) GW -100 $\mathrm{cm},(\mathrm{b}) \mathrm{GW}-150 \mathrm{~cm}$, (c) GW $-200 \mathrm{~cm}$, and (d) free drainage. 
satellite scales. The Brown (1 Apr.- 31 Oct. 2002, Illinois), Walnut Creek (WC) 11 to 14 (1 May-31 Oct. 2002, Iowa), and Lubbock (1 Mar.-31 July 2002, Texas) sites were selected for the field validations. Vegetation cover at the field sites consisted of corn (WC 11 and WC 12), soybean [Glycine max (L.) Merr.] (WC 13 and WC 14), and native grass (Brown and Lubbock). Vegetation characteristics for the study sites are shown in Table 2. In situ SM data (13 d for the Brown site and $11 \mathrm{~d}$ for the WC 14 site) from the International Soil Moisture Network (http://ismn.geo. tuwien.ac.at/) and the Soil Moisture Experiment 2002 (SMEX02: http://nsidc.org/) were measured by the neutron and theta probe techniques, respectively. Airborne PSR (800- by 800-m footprint) SM data sets (for $10 \mathrm{~d}$ ) (Bindlish et al., 2006) during the SMEX02 were used for the WC sites. For the larger scale, we used the AMSR-E ( 25- by 25-km footprint; Njoku [2008]) SM products (soil depth of $0-1 \mathrm{~cm}$ ) for $7 \mathrm{~d}$ at the Lubbock site.

For validation at the point scale, we used ET measurements (Prueger et al, 2009) collected by the eddy covariance (EC) tower (located within the WC 14 site) during the Soil Moisture Atmospheric Coupling Experiment in Iowa from 19 June through 9 July 2002. The RS-based (cloud-free) ET (4-6 d during the simulation period because of the limited availability of MODIS data sets due to weather conditions and scanning intervals) for the Brown, WC 11 to 14, and Lubbock sites were estimated by the SEBAL model, which computes pixel-scale ET products using MODIS data (Bands 1-7, land surface temperature; Bands 31 and 32, emissivities; see details in Table 3) with crop height and wind speed at field sites. Unfortunately, validation for the SEBAL-based ET products is limited compared with available tower-based ET measurements that can represent the airborne and satellite scales; however, the WC 14 site had a uniform soybean cover, indicating that the tower-based ET measurements could represent the spatially distributed ET at the MODIS scale ( 500 by $500 \mathrm{~m}$ ). Under this assumption, we validated the SEBAL-based ET products with the tower-based ET measurements. Additionally, the RS-based ET estimates using a different data source (LANDSAT, 30 by $30 \mathrm{~m}$ ) and the S-SEBI (Roerink et al., 2000) model were also compared to prove the reliability of the ET images calculated by SEBAL.

Daily weather data (e.g., precipitation, wind speed, maximum and minimum temperature, relative humidity, and solar radiation) were collected from the Soil Climate Analysis Network (http:// www.wcc.nrcs.usda.gov/scan/) in Iowa and the Illinois Climate Network (http://www.isws.illinois.edu/warm/datatype.asp) in Illinois. For the Lubbock site, we used precipitation data from the Tropical Rainfall Measuring Mission (http://trmm.gsfc.nasa.gov/), which has the same resolution as the AMSR-E products.

The limitation of this field validation study is the resolution discrepancy between PSR-based soil moisture ( 800 by $800 \mathrm{~m}$ ) and MODIS-based ET ( 500 by $500 \mathrm{~m}$ ) products. Also, the initial and bottom boundary conditions were unknown at the field sites. Thus,
Table 2. Vegetation characteristics for the Walnut Creek (WC 11-14, Iowa), Bondville (Illinois), and Lubbock (Texas) sites.

$\begin{array}{llll}\text { Site } & \text { Crop } & \text { Crop height } & \text { Max. root depth } \\ & & 1.42-1.45 & 0.75 \\ \text { WC 11 } & \text { corn } & 1.42-1.45 & 0.75 \\ \text { WC 12 } & \text { corn } & 0.29-0.36 & 0.60 \\ \text { WC } 13 & \text { soybean } & 0.29-0.36 & 0.60 \\ \text { WC } 14 & \text { soybean } & 0.30 & 0.90-1.20 \\ \text { Bondville } & \text { native grass } & 0.30 & 0.90-1.20 \\ \text { Lubbock } & \text { native grass } & & \end{array}$

Table 3. Description of the Moderate Resolution Imaging Spectroradiometer (MODIS) data.

\begin{tabular}{ll}
\hline Image character & Values \\
\hline $\begin{array}{l}\text { Platform } \\
\text { Acquisition date } \\
\text { (Day of Year) }\end{array}$ & BQUA/TERRA \\
& Walnut Creek, IA $(153,185,225,233,257)$ \\
& Lubbock, TX $(65,73,129,137,167)$ \\
Reference system & latitude, longitude \\
Resolution & Bands $1-7,500$ by $500 \mathrm{~m}$ \\
& Land surface temperature, 1000 by $1000 \mathrm{~m}$ \\
& Emissivity product, 1000 by $1000 \mathrm{~m}$ \\
\hline
\end{tabular}

we tested our approach with various combinations of initial and bottom boundary conditions such as groundwater table depths of $-200,-150 \mathrm{~cm},-100 \mathrm{~cm}$ from the soil surface and selected the best conditions (GW $-150 \mathrm{~cm}$ for the WC 11-14 sites and GW -200 $\mathrm{cm}$ for the Brown and Lubbock sites) that had the highest fitness for the individual sites. We assumed that the initial conditions $[h(z, t=0)=-150 \mathrm{~cm}$ for the WC $11-14$ sites and $h(z, t=0)=$ $-200 \mathrm{~cm}$ for the Brown and Lubbock sites] were in equilibrium with the groundwater tables.

Pearson's correlation $(R)$ and the root mean square error (RMSE) of the observed and simulated SM and ET were used to evaluate our numerical and field validation experiments of the inverse modeling based data assimilation (using linked NMCGA and SEBAL) algorithm.

$$
\begin{aligned}
& R=\frac{\sum_{t=1}^{T}\left(\theta_{\text {sim }, t}-\left\langle\theta_{\text {sim }}\right\rangle\right)\left(\theta_{\text {obs }, t}-\left\langle\theta_{\text {obs }}\right\rangle\right)}{\left[\sum_{t=1}^{T}\left(\theta_{\text {sim }, t}-\left\langle\theta_{\text {sim }}\right\rangle\right)^{2} \sum_{t=1}^{T}\left(\theta_{\text {obs }, t}-\left\langle\theta_{\text {obs }}\right\rangle\right)^{2}\right]^{1 / 2}} \\
& \text { RMSE }=\left[\frac{\sum_{t=1}^{T}\left(\theta_{\text {obs }, t}-\theta_{\text {sim }, t}\right)^{2}}{T}\right]^{1 / 2}
\end{aligned}
$$

where $\theta_{\text {sim }, t}$ is the simulated soil moisture with the time index $(t),<\theta_{\text {sim }}>$ is the average soil moisture of the $\theta_{\text {sim }, t}, \theta_{\text {obs }, t}$ is the observed soil moisture with the time index $(t)$, and $\left\langle\theta_{\text {obs }}>\right.$ is the 
average soil moisture of the $\theta_{\text {obs, }, *}$. Also, we added the $P$ value (5\%) for correlation of the field experiments.

\section{Results and Discussion Case 1: Homogeneous Column with Free Drainage}

Table 4 shows the summary of solutions $\left[\mathrm{P}^{*}: \mu(\alpha), \mu(n), \mu\left(\theta_{\text {res }}\right)\right.$, $\left.\mu\left(\theta_{\text {sat }}\right), \mu\left(K_{\text {sat }}\right)\right]$ for the numerical experiments derived by the proposed data assimilation algorithm under the ET-only, SM-only, and $S M+E T$ criteria for the different soil textures and a corn crop cover for the Case 1 scenario. The estimated soil hydraulic parameters are shown in terms of their arithmetic means (3 ensembles $\times 30$ realizations) and \pm 95 PCI.

In general, the shape $(\alpha)$ parameters under most conditions (described by the three criteria) for the sandy loam soil closely identified with the target values, while the estimated $(n)$ parameters were more variable. The scaling parameters $\left(\theta_{\text {res }}\right.$ and $\left.\theta_{\text {sat }}\right)$ under the SM-only and SM + ET criteria were better than those of the ET-only criterion, suggesting that the latter had more uncertainty. The $K_{\text {sat }}$ values under all the criteria were considerably overestimated compared with the target values, but it is apparent that the $K_{\text {sat }}$ value estimated under the $S M+$ ET criterion was better than those of the ET-only and SM-only criteria. Figure 4 shows the $\theta(b)$ and $K(b)$ functions derived by the estimated soil hydraulic parameters (Table 4) for the sandy loam soil. The $\theta(b)$ functions under all the criteria appeared to be identifiable with the observations, but the $K(b)$ functions had more (mean) bias errors. Uncertainties of the $K(b)$ values under the ET-only and SM-only criteria were considerably higher than the target values. The SM + ET criterion also had variations in the $K(b)$ function; however, the estimated values were closer to the observations than those of the SM-only and ET-only criteria because the target value was only adequately defined in a range of $\pm 95 \mathrm{PCI}$ under the $\mathrm{SM}+\mathrm{ET}$ criterion. This might imply that adding an ET component in the near-surface soil moisture assimilation algorithm improved the estimates of the $K(b)$ functions.

For the silt loam soil, the $\alpha$ and $\theta_{\text {res }}$ values under the ET-only and SM-only criteria matched well with the target values. In contrast, for the SM + ET criteria, only a was predictable with high accuracy. The $K_{\text {sat }}$ value fared better in performance under the $\mathrm{SM}+\mathrm{ET}$ criterion and the SM-only criterion, while the ET-only criterion showed large uncertainties. The $\theta(b)$ functions under the SM-only and SM + ET criteria were found to be superior to those obtained for the ET-only criteria, as shown in Fig. 5. But the uncertainty boundaries ( $\pm 95 \mathrm{PCI})$ for the $\theta(b)$ functions under the SM + ET criterion were smaller than those of the ET-only and SM-only criteria. The most profound impact of the ET component is visible in the $K(b)$ functions because variations of the simulated $K(b)$ function under the SM + ET criterion are considerably decreased compared with those of the SM-only and ET-only criteria.

Table 4. Solutions for sandy loam, silt loam, and clay loam soils under the evapotranspiration (ET)-only, soil moisture (SM)-only, and SM + ET criteria (synthetic conditions) in Case 1 (maximum generations: 30; number of chromosomes in a generation: 10; number of ensembles: 3; number of resamplings: 30$)$.

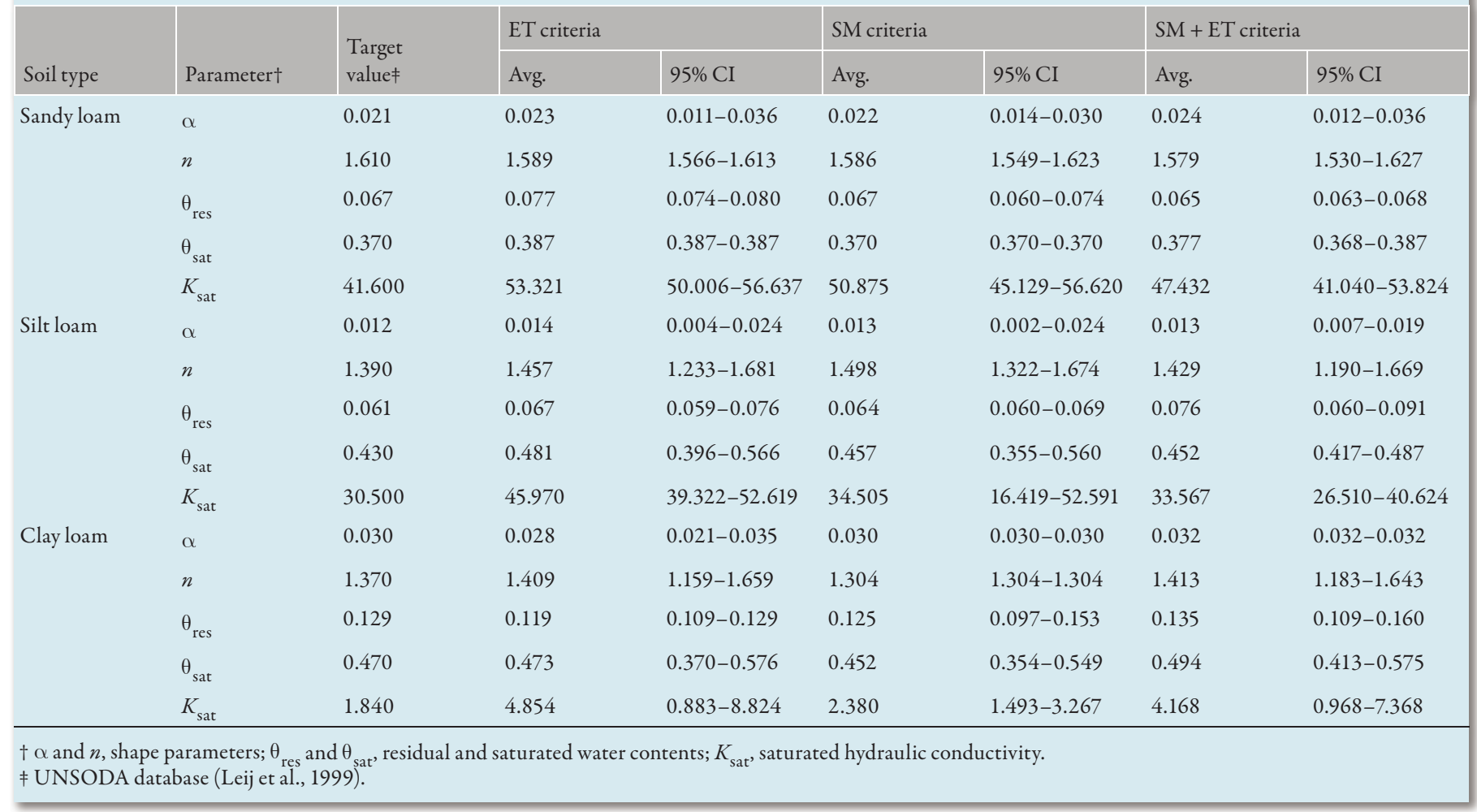


For clay loam soil (see Fig. 6), the $\alpha$ and $\theta_{\text {sat }}$ values under the ET-only criterion were easily identifiable with the target values, but the $n, \theta_{\text {res }}$, and $K_{\text {sat }}$ estimates were relatively less clear (Table $4)$. The $\alpha, \theta_{\text {res }}$, and $K_{\text {sat }}$ values under the SM-only criterion matched the target values well. Only the $\alpha$ value under the SM + ET criterion matched well with the observation, unlike the solutions for the sandy loam and silt loam soils. Figure 6 shows the $\theta(b)$ and $K(b)$ functions of the clay loam soil for all the criteria considered. The $\theta(b)$ and $K(b)$ functions estimated under the SM-only criterion were slightly better than those for the ET-only and SM + ET criteria. Also, uncertainties of \pm 95PCI under the SM-only criterion were narrow compared with those for the ET-only and SM + ET criteria. Figure 6d shows the sample comparisons of observed and simulated ET for the ET-only criteria for the clay loam soil under the synthetic condition. Note that the ET comparisons for the sandy loam and silt loam soils are not (a)
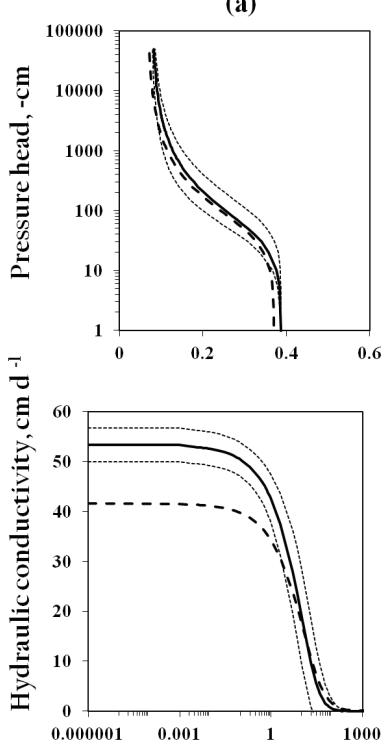

(b)

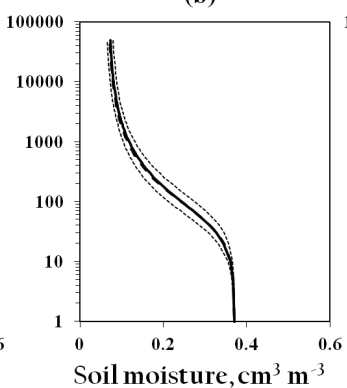

(c)

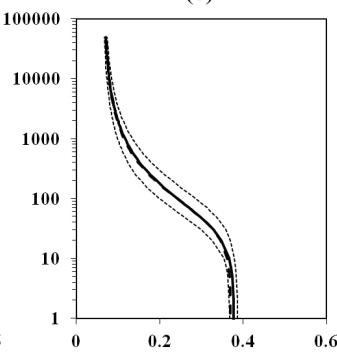

- - - Target $\theta(h)$

- Average $\theta(h)$

......... 95 $95 \mathrm{PCI}$

…..... 95PCI-
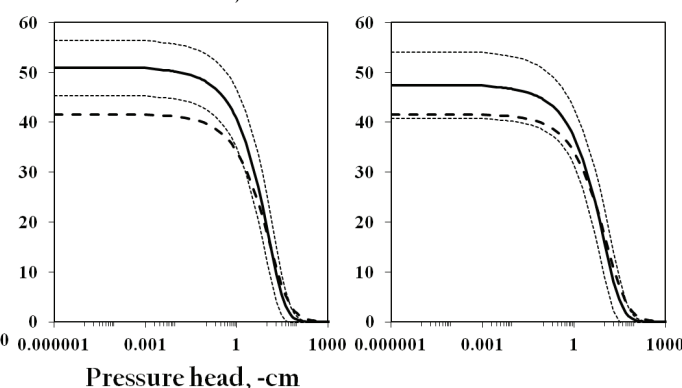

Fig. 4. Soil water retention $\theta(b)$ and hydraulic conductivity $K(b)$ functions from Monte Carlo simulations for a sandy loam soil under the synthetic conditions: (a) evapotranspiration (ET)-only criterion, (b) soil moisture (SM)-only criterion, and (c) SM + ET criterion; PCI is percent confidence interval.

(a)
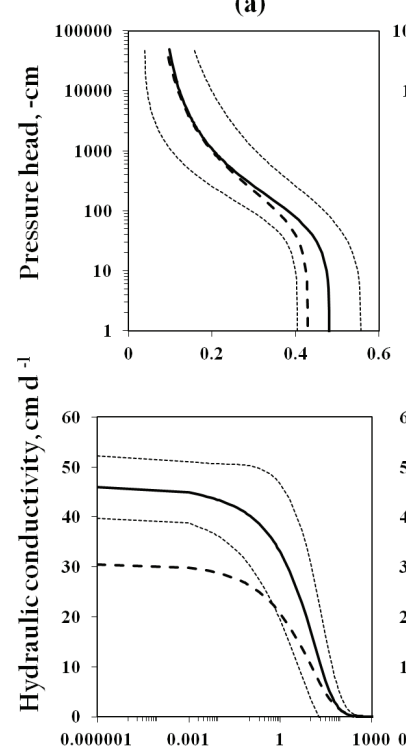

(b)

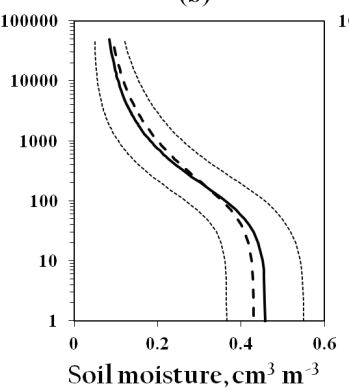

(c)

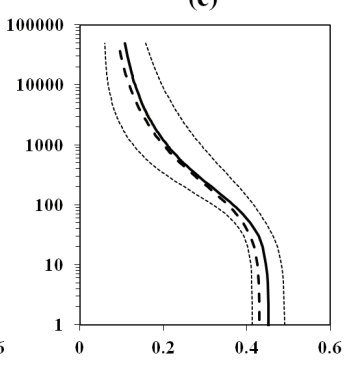

- - - Target $\theta(h)$

- Average $\theta(h)$

........ 95PCI+

........ 95PCI-
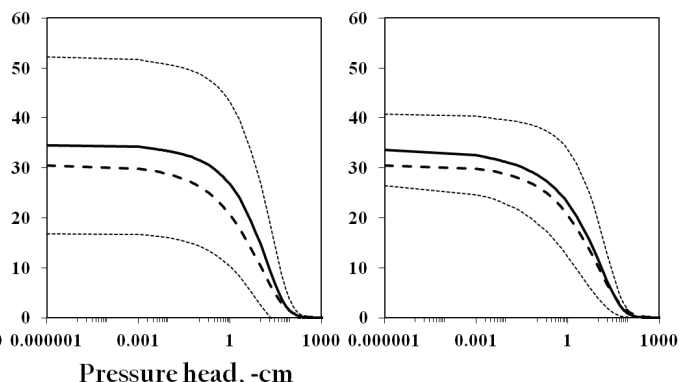

- - - Target $K(h)$

- Average K(h)

$95 \mathrm{PCI}+$

95PCI-

Fig. 5. Soil water retention $\theta(b)$ and hydraulic conductivity $K(b)$ functions from Monte Carlo simulations for a silt loam soil under the synthetic conditions: (a) evapotranspiration (ET)-only criterion, (b) soil moisture (SM)-only criterion, and (c) SM + ET criterion; PCI is percent confidence interval, DOY is Day of the Year. 
(a)
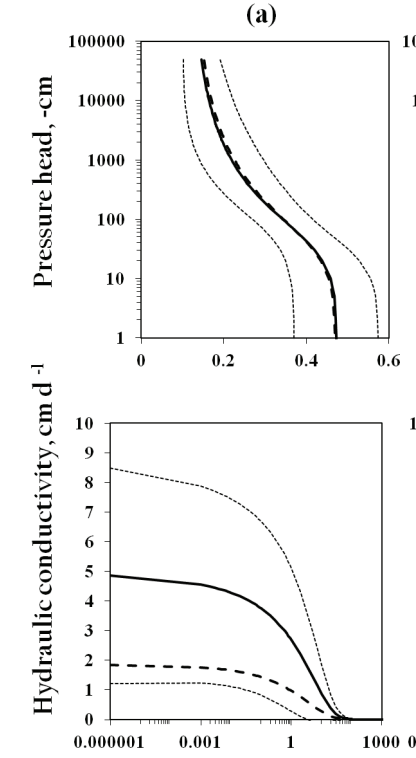

(b)
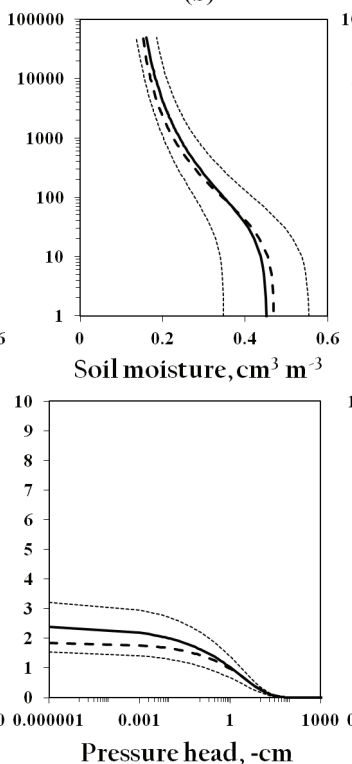

(c)
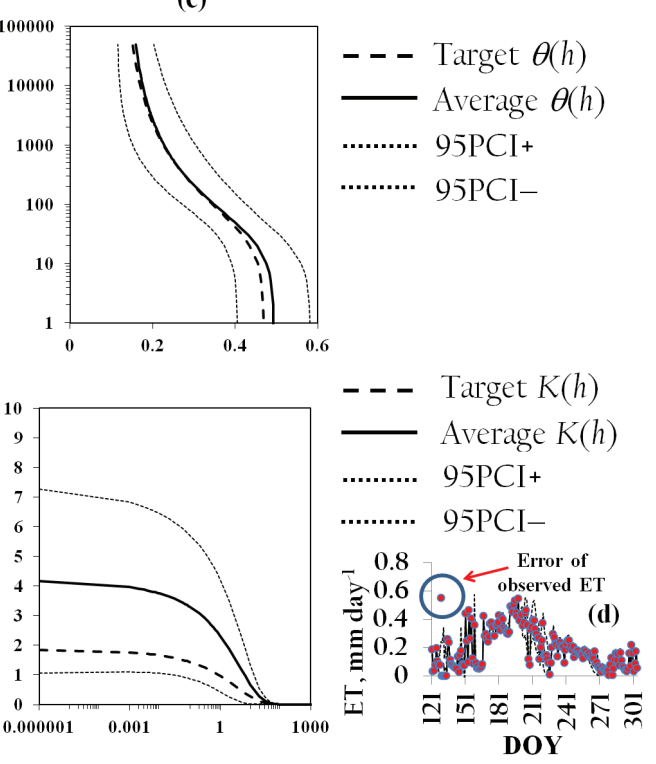

Fig. 6. Soil water retention $\theta(b)$ and hydraulic conductivity $K(b)$ functions from Monte Carlo simulations for a clay loam soil under the synthetic conditions: (a) evapotranspiration (ET)-only criterion, (b) soil moisture (SM)-only criterion, (c) SM + ET criterion, and (d) comparison of observed and simulated ET estimates under the ET-only criterion; PCI is percent confidence interval.

presented for the sake of brevity. For Day of the Year (DOY) 129, the extremely high (synthetic or observed) ET value $\left(0.55 \mathrm{~mm} \mathrm{~d}^{-1}\right)$ was generated in this numerical study due to inherent drawbacks of the adopted hydrologic model. This may imply that an error in ET influences uncertainties in the parameter estimation and modeling performance for a clay loam soil in the unsaturated zone. Although the simulated $K(b)$ functions of the ET-only and SM + ET criteria had bias (caused by an unusual synthetic or observed ET value), the simulated $\theta(b)$ functions still corresponded well to the target values. The results for the clay loam soil indicate that the hydraulic conductivity function $[K(b)]$ is more sensitive to the ET component than the soil water retention function $[\theta(b)]$.

Overall, most of the $\theta(b)$ and $K(b)$ functions under the SM + ET criterion were more identifiable than those for the ET-only and SM-only criteria, and the effect of the ET component was relatively less sensitive to $\theta(b)$ than $K(b)$. The comparison of these results for the SM-only and SM + ET criteria provides significant inferences with respect to soil parameterizations using physically based hydrologic models. Existing parameterization-based approaches use only soil moisture observations to derive soil parameters. In general, root zone SM dynamics limit ET near the land surface in the field. Because the soil properties limit root zone SM, ET might infer soil properties indirectly by its link to soil moisture in the root zone. Thus, the ET component could play a role as a surrogate variable that can affect the processes occurring in the (deep) root zone (Pollacco and Mohanty, 2012). On the basis of these findings, we suggest that considering both the SM and ET components in the parameter estimations considerably improved (reduced) the uncertainties of the estimated $\theta(b)$ and $K(b)$ functions across the soil profile.
Under the synthetic conditions, we could test the model performance excluding measurement errors, but the model outputs had limitations in considering the complexity of actual field conditions. Thus, we added the proper error amounts $( \pm 10,20$, and $30 \%$ of the average values for SM and ET) to the synthetic results (shown only for a sandy loam soil in Fig. 7) under the SM + ET criterion. The soil moisture $(R=0.996$ and RMSE $=0.009)$ and evapotranspiration $(R=0.999$ and RMSE $=0.005)$ dynamics for the sandy loam soil were matched well with the synthetic observations. Figure 8 shows the root zone soil moisture in the deeper soil depth $(180-200 \mathrm{~cm})$ for the three soil textures. For the sandy loam soil, the simulated soil moisture dynamics under the SM-only $(\mathrm{RMSE}=0.001)$ and SM + ET $($ RMSE $=0.004)$ criteria matched well with the target values, but the soil moisture predictions for the ET-only criterion (RMSE $=0.010)$ were overestimated compared with the true values. We confirmed similar trends for the silt loam and clay loam soils as well. The root zone soil moisture estimates under the SM + ET criterion for the silt loam $($ RMSE $=0.008)$ and clay loam (RMSE $=0.002)$ soils were closer to the target values than those for the ET-only (RMSE $=0.015$ and 0.008 for silt loam and clay loam, respectively) and SM-only (RMSE $=0.011$ and 0.004 for silt loam and clay loam, respectively) criteria. Although these results were derived under the synthetic conditions, they might suggest that improvement in the predictive ability for soil moisture at deeper soil depths is attributable to the ET component. These findings may beg a question for soil parameterization approaches based on the inverse model in the vadose zone because the inversion model estimates the effective soil hydraulic parameters that can represent the whole soil profile $(0-200 \mathrm{~cm}$ in this study) by using only the 
$R: 0.996, R M S E: 0.009$
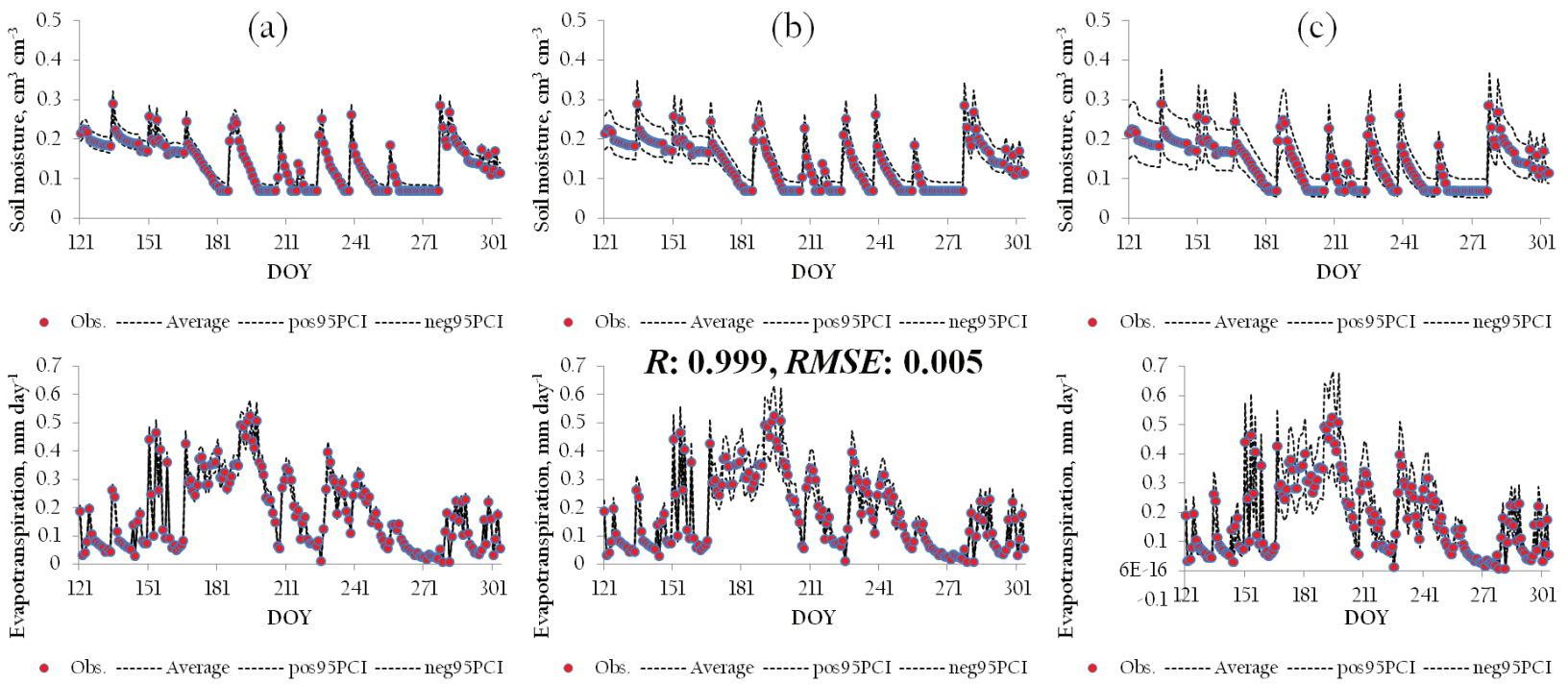

Fig. 7. Estimated root zone soil moisture (SM) and evapotranspiration (ET) for a sandy loam soil under the SM + ET criterion (synthetic conditions) with the error ranges of ensemble outputs: (a) $\pm 10 \%$, (b) $\pm 20 \%$, and (c) $\pm 30 \%$ errors of the averaged ensemble; Obs. is observed; PCI is percent confidence interval, pos is positive, neg is negative.

near-surface $(0-1$ or $0-5 \mathrm{~cm})$ soil moisture estimates from airborne or satellite RS platforms. Uncertainties may result in identifying the soil hydraulic parameters as the soil depth increases due to textural layering, rooting depth and density, pore-size distribution, etc. Summarily, the results of Case 1 indicate that our proposed approach including the ET component (with SM), which provides more information on the unsaturated zone hydrologic behavior, improved the estimates of the effective soil hydraulic parameters.

\section{Case 2: Homogeneous Soil Column with Shallow Groundwater Table}

We conducted the Case 2 scenario to evaluate the impact of the ET component in the presence of a shallow groundwater table $(-100 \mathrm{~cm}$ from the soil surface) in the homogeneous soil column under the SM-only and SM + ET criteria (the ET criterion was excluded). Table 5 shows the derived effective soil hydraulic parameters for Case 2 .

For the sandy loam soil, the soil hydraulic parameters under the SM + ET criterion matched the true values better than those for the SM-only criterion except for $\theta_{\text {res }}$ and $\theta_{\text {sat }}$. Although the standard deviation of $K_{\text {sat }}$ under the SM + ET criterion was slightly higher than for the SM-only criterion, the average value of $K_{\text {sat }}$ was estimated more successfully. The results for the silt loam soil showed similar trends to the findings for the sandy loam soil. The $\alpha, n, \theta_{\text {res }}$ and $\theta_{\text {sat }}$ values under the $S M+$ ET criterion were identifiable with the target values, while only the $\alpha$ value matched well under the SM-only criterion. The $K_{\text {sat }}$ value under the SM-only criterion had large uncertainties compared with the $S M+$ ET criterion. Usually, the model performance for the silt loam soil had more uncertainties than the sandy loam and clay loam soils (Ines and Mohanty, 2008a; Shin et al., 2012). As shown in Fig. 4 to 6, the nonlinear characteristics of the water retention curve for the silt loam soil and its particular correspondence with root water uptake might cause more uncertainties in the parameter estimations. In this study, when the ET component was included in quantifying the effective soil hydraulic properties, the solutions for the silt loam soil with a shallow groundwater table were improved. For the clay loam soil, the parameters under the SM + ET criterion were perfectly identified with the target value, while the $n$ value had small variations; however, the $\alpha$ and $\theta_{\text {res }}$ values under the SM-only criterion were the only ones that matched well. In general, the SM + ET criterion performed better in predicting the soil hydraulic parameters and reduced their uncertainties compared with the SM-only criterion under the shallow groundwater table condition.

Overall, the solutions with the shallow groundwater table depth of $-100 \mathrm{~cm}$ were not as well identified as those under the free drainage condition, indicating that the parameter estimations had more uncertainties in the soil profile dominated by upward flows from the shallow groundwater table than the free drainage condition. Based on the results of Case 2, we suggest that this approach could reflect the hydrologic condition in the unsaturated zone affected by both the top (atmospheric) and bottom boundary conditions.

\section{Case 3: Field Validation Experiments}

In Case 3, we tested the applicability of the linked NMCGA and SEBAL algorithm under the SM-only and SM + ET criteria at various spatial scales under the field conditions. For validation of pixel-scale ET data, we compared the SWAP model based ET estimates at the airborne scale (WC 14) under the SM + ET 

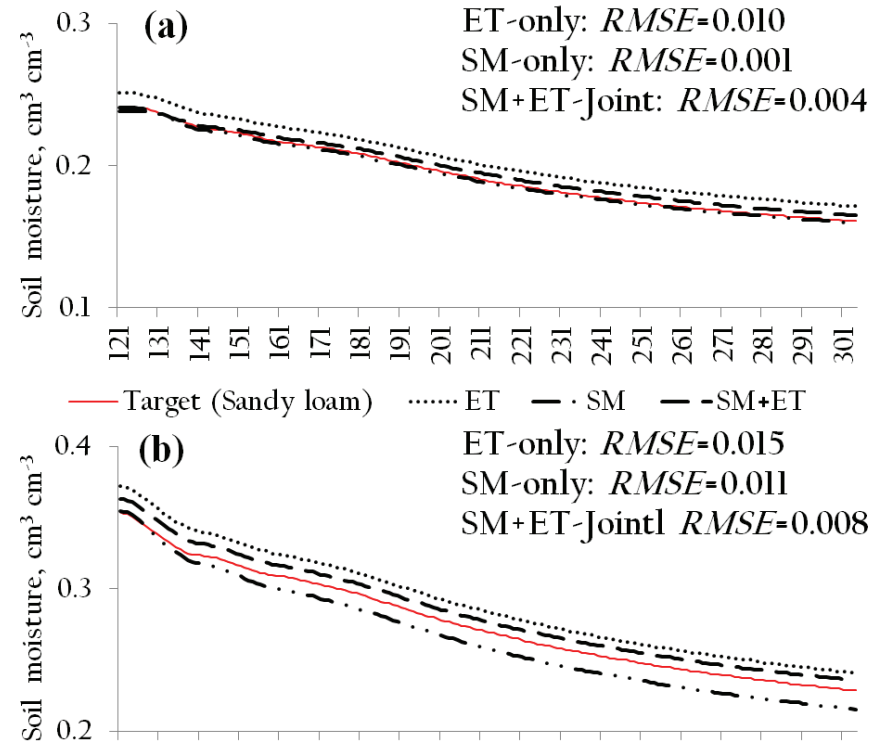

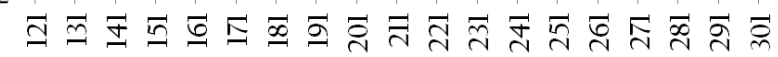

— Target (Silt loam) …...ET - . SM - -SM+ET

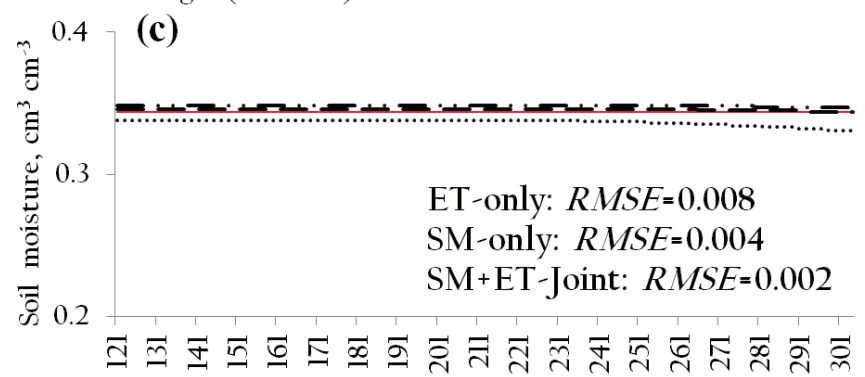

— Target (Clay loam) …... ET - . SM - -SM+ET

Fig. 8. Comparisons of the deep soil moisture dynamics (180-200 $\mathrm{cm})$ for sandy loam, silt loam, and clay loam soils under the synthetic conditions: (a) evapotranspiration (ET)-only criterion, (b) soil moisture (SM)-only criterion, and (c) SM + ET criterion. criterion with not only the RC-based measurements but also the SEBAL- and S-SEBI-based ET estimates (Fig. 9). Overall, the SWAP-based ET estimates matched well with the RS-based observations ( $R=0.597$ for EC, $R=0.933$ for S-SEBI, and $R=0.944$ for SEBAL). The correlation with the EC-based measurements was relatively lower because the ET measurements on DOY 176 and 178 were considerably lower than the others (i.e., DOY 175, 177, and 179). This might indicate that the EC ET data had measurement errors; however, the SWAP-based ET data $($ RMSE $=0.667)$ had less uncertainty than those of S-SEBI and SEBAL (RMSE $=0.966$ and 1.200). Although we compared the SWAP-based ET estimates at the airborne scale (WC 14) under the SM + ET criterion with the EC measurements and RS-based ET data (S-SEBI and SEBAL), these findings could show the reliability of our approach and pixel-scale ET estimates. Table 6 presents the statistics of simulated SM and ET compared with the measurements. Overall, the statistics ( $R$ and RMSE) for the $\mathrm{SM}$ and ET estimates under the SM + ET criterion showed good performance and were generally better than those under the SM-only criterion. These field validation results support the robustness of this approach as shown in the synthetic results for Case 1, indicating that considering the SM and ET components jointly improved the hydrologic model outputs more than the SM-only criterion and reduced their uncertainties.

Figure 10 shows the observed and simulated results (SM and ET) at different spatial scales (point and airborne scales for WC 14 in Iowa and the satellite scale for Lubbock in Texas) under the $S M+E T$ criterion. At the point scale, the simulated SM estimates $(R=0.885$ and RMSE $=0.033)$ matched well with the measurements. At the footprint scale, the model estimated SM dynamics $(R=0.785$ and $\mathrm{RMSE}=0.044)$ matched relatively well

Table 5. Solutions for a homogenous soil column with a shallow water table depth of $-100 \mathrm{~cm}$ for sandy loam, silt loam, and clay loam soils under the soil moisture (SM) and SM + evapotranspiration (ET) criteria (synthetic conditions) in Case 2.

\begin{tabular}{|c|c|c|c|c|c|c|}
\hline \multirow[b]{2}{*}{ Soil type } & \multirow[b]{2}{*}{ Parameter $\dagger$} & \multirow{2}{*}{$\begin{array}{l}\text { Target } \\
\text { value }\end{array}$} & \multicolumn{2}{|l|}{ SM } & \multicolumn{2}{|c|}{$\mathrm{SM}+\mathrm{ET}$} \\
\hline & & & Avg. & SD & Avg. & SD \\
\hline \multirow{5}{*}{ Sandy loam } & $\alpha$ & 0.021 & 0.029 & 0.000 & 0.016 & 0.005 \\
\hline & $n$ & 1.610 & 1.399 & 0.118 & 1.510 & 0.055 \\
\hline & $\theta_{\text {res }}$ & 0.067 & 0.074 & 0.009 & 0.080 & 0.013 \\
\hline & $\theta_{\text {sat }}$ & 0.370 & 0.370 & 0.000 & 0.471 & 0.037 \\
\hline & $K_{\text {sat }}$ & 41.600 & 50.157 & 2.274 & 38.422 & 3.042 \\
\hline \multirow[t]{5}{*}{ Silt loam } & $\alpha$ & 0.012 & 0.013 & 0.006 & 0.013 & 0.002 \\
\hline & $n$ & 1.390 & 1.591 & 0.012 & 1.397 & 0.115 \\
\hline & $\theta_{\text {res }}$ & 0.061 & 0.082 & 0.011 & 0.067 & 0.003 \\
\hline & $\theta_{\text {sat }}$ & 0.430 & 0.456 & 0.048 & 0.445 & 0.055 \\
\hline & $K_{\text {sat }}$ & 30.500 & 45.642 & 5.276 & 36.049 & 5.050 \\
\hline \multirow[t]{5}{*}{ Clay loam } & $\alpha$ & 0.030 & 0.033 & 0.000 & 0.031 & 0.002 \\
\hline & $n$ & 1.370 & 1.386 & 0.145 & 1.401 & 0.135 \\
\hline & $\theta_{\text {res }}$ & 0.129 & 0.127 & 0.015 & 0.130 & 0.004 \\
\hline & $\theta_{\text {sat }}$ & 0.470 & 0.486 & 0.014 & 0.472 & 0.054 \\
\hline & $K_{\text {sat }}$ & 1.840 & 4.522 & 0.880 & 2.050 & 0.055 \\
\hline
\end{tabular}

† $\alpha$ and $n$, shape parameters; $\theta_{\text {res }}$ and $\theta_{\text {sat }}$, residual and saturated water contents; $K_{\text {sat }}$, saturated hydraulic conductivity. 
with the PSR-based soil moisture measurements. Compared with those at the point scale, the $\mathrm{RS}$ footprint scale results had more uncertainty. Footprint-scale discrepancy could be attributed to the data qualities of the specific pixels, weather conditions and variations within the pixel, and discrepancy between the PSR and MODIS scales for input data. The observed (PSR) and simulated SM trends show a good match with the rainfall pattern, however, indicating that the pixel-based SM at the field scale reflects well the spatial correspondence. Because the PSR-based SM values were not matched well with the model outputs during the period DOY 186 to 192 , uncertainties were relatively increased. The observed and simulated SM dynamics at the satellite scale were relatively lower than those at the point and airborne scales. Although various uncertainties from the heterogeneity of areal soil textures and vegetation cover across the land surface were included in a remote sensing pixel, the results $(R=0.569$ and RMSE $=0.060)$ matched well with the measurements.

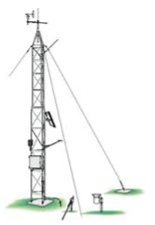

(a) Tower-based eddy covariance (EC) ET

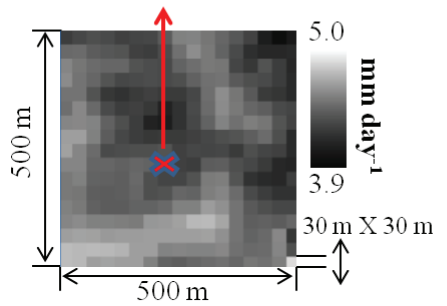

Averaged ET of the sub-pixels:

$4.5 \mathrm{~mm}$ day $^{-1}$

(b) S-SEBI-based ET (DOY 182)

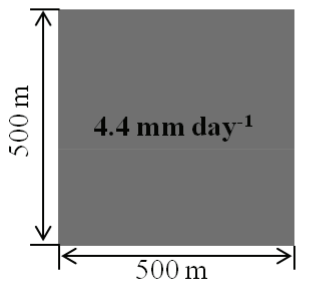

(c) SEBAL-based ET (DOY 185)

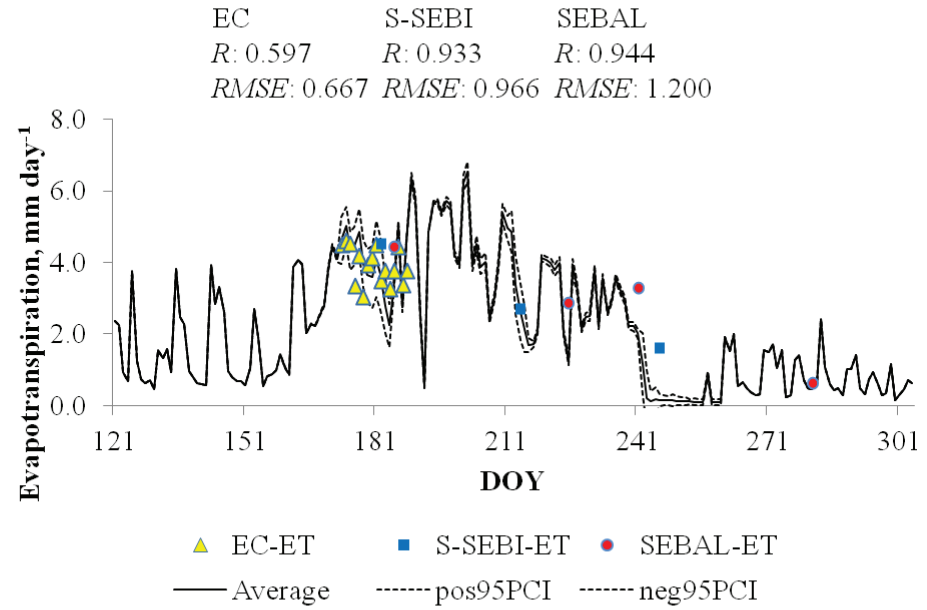

Fig. 9. Comparison of the evapotranspiration (ET) dynamics of (a) eddy covariance, (b) the simplified Surface Energy Balance Index (S-SEBI), and (c) Surface Energy Balance Algorithm for Land (SEBAL) with the simulated ET estimates (Polarimetric Scanning Radiometer based soil moisture and SEBAL-based ET were used) based on the linked NMCGA and SEBAL data assimilation approach at the WC 14 site; DOY is Day of the Year.

Table 6. Correlation $(R)$ and RMSE of the pixel-based (in situ), simulated soil moisture (SM) and evapotranspiration (ET) under the SM and SM + ET criteria at the Brown, Walnut Creek (11-14), and Lubbock sites for Case 3.

\begin{tabular}{|c|c|c|c|c|c|c|c|c|}
\hline \multirow[b]{2}{*}{ Site } & \multicolumn{4}{|l|}{ SM criteria } & \multicolumn{4}{|c|}{$\mathrm{SM}+\mathrm{ET}$ criteria } \\
\hline & $R$ & RMSE & $R\left(p\right.$ value $\left.^{*}\right)$ & RMSE & $R\left(p\right.$ value $\left.{ }^{*}\right)$ & RMSE & $R\left(p\right.$ value $\left.{ }^{*}\right)$ & RMSE \\
\hline WC $14 \dagger$ & $0.882(0.604) \neq$ & 0.035 & $0.513(0.026)$ & 0.908 & $0.885(0.740)$ & 0.033 & $0.568(0.093)$ & 0.784 \\
\hline Brown§ & $0.927(0.879)$ & 0.085 & $0.874(0.856)$ & 1.663 & $0.936(0.598)$ & 0.101 & $0.874(0.856)$ & 0.990 \\
\hline WC 11g & $0.777(0.461)$ & 0.050 & $0.955(0.499)$ & 0.554 & $0.781(0.531)$ & 0.047 & $0.952(0.545)$ & 0.500 \\
\hline WC 13 & $0.777(0.239)$ & 0.054 & $0.954(0.407)$ & 1.022 & $0.782(0.272)$ & 0.054 & $0.949(0.438)$ & 0.978 \\
\hline WC 149 & $0.784(0.559)$ & 0.045 & $0.943(0.317)$ & 1.208 & $0.785(0.501)$ & 0.044 & $0.944(0.320)$ & 1.200 \\
\hline Lubbock\# & $0.537(0.156)$ & 0.053 & $0.600(0.221)$ & 1.316 & $0.569(0.113)$ & 0.060 & $0.665(0.185)$ & 1.296 \\
\hline
\end{tabular}

† In situ soil moisture and eddy covariance ET measurements were used for the Walnut Creek (WC 14) site in Iowa.

$\neq P$ values in parentheses.

$\S$ In situ soil moisture and pixel-based ET data sets were used for the Brown site in Illinois.

I Pixel-based (Polarimetric Scanning Radiometer) soil moisture and ET data sets were used for the Walnut Creek (WC 11-14) sites in Iowa.

\# Pixel-based (Advanced Microwave Scanning Radiometer-Earth Observing System) soil moisture and ET data sets were used for the Lubbock site in Texas. 
(a)

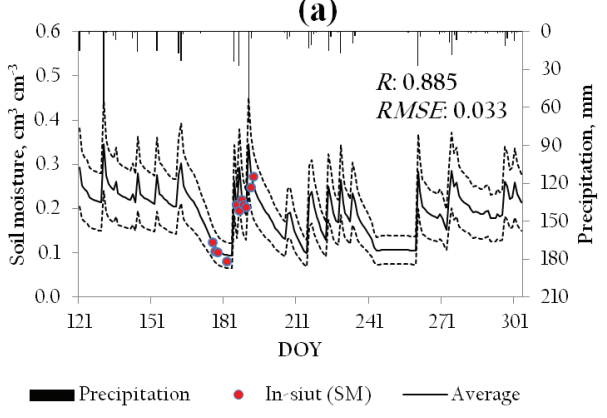

----- posError (30\%) ------ negError (30\%)

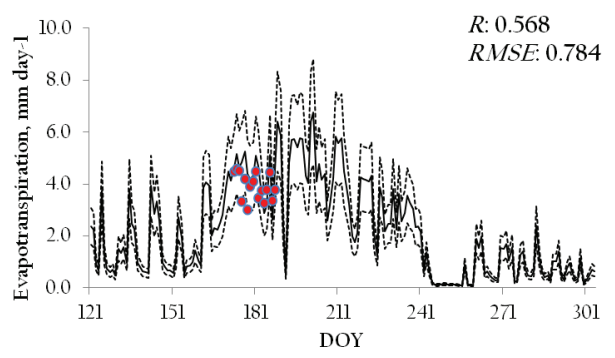

- $\mathrm{EC}(\mathrm{ET}) \quad$ Average

-----posError (30\%) ------negError (30\%) (b)

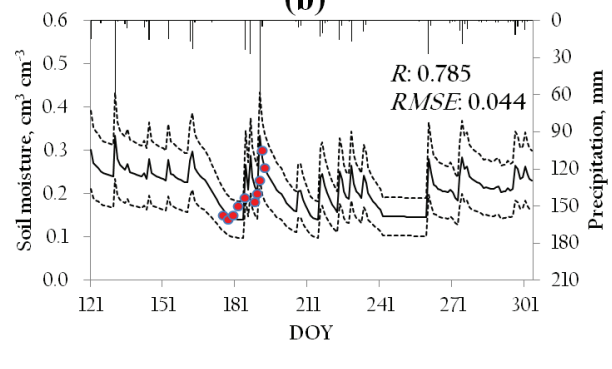

Precipitation
-----p posError (30\%) ------- negError (30\%)

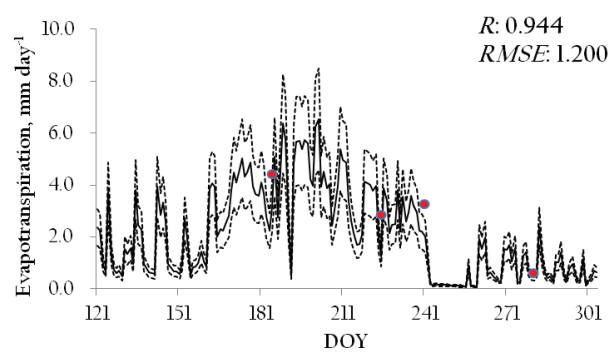

- SEBAi(ET) - Average

------ posError (30\%) ------- negError (30\%) (c)
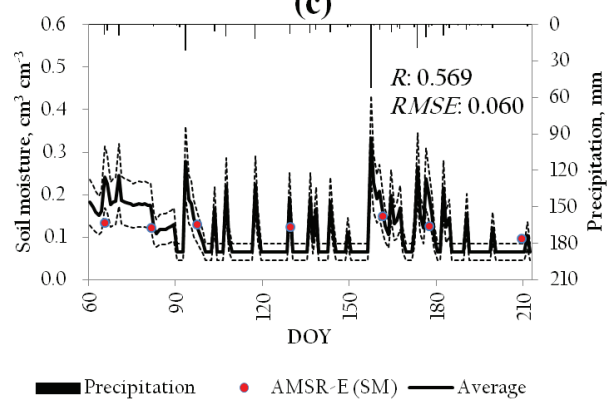

------p posError (30\%) ------ negError (30\%)

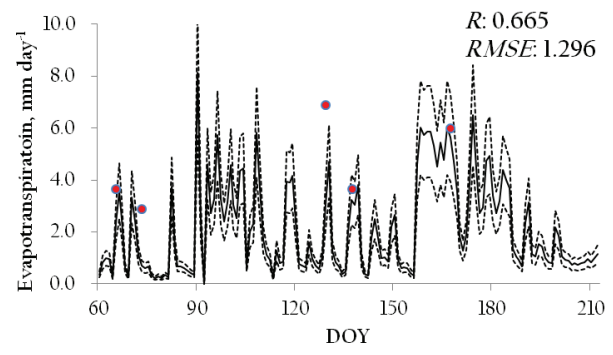

- $\operatorname{SEBAI}(\mathrm{ET}) \quad$ Average

------ posError (30\%) ------- negError (30\%)

Fig. 10. Comparisons of the observed and simulated soil moisture (SM) and evapotranspiration (ET) at different scales using the linked NMCGA and SEBAL algorithm under the SM + ET criterion: (a) point-scale (in situ) SM and eddy-covariance ET at the WC 14 site, (b) airborne-scale (Polarimetric Scanning Radiometer) pixel-based SM and ET at the WC 14 site, and (c) satellite-scale (Advanced Microwave Scanning Radiometer-Earth Observing System) pixel-based SM and ET at the Lubbock site.

These results show how the parameter estimations have variability at different spatial scales. As the scale increased from the point to satellite scale, the results had more uncertainty (RMSE $=0.033-0.060$ for SM). This might indicate that airborne- or satellite-scale SM products have uncertainties due to the land surface variability, especially satellite-scale products. However, the RMSE value at the Brown site (0.101) was relatively higher than that of the WC 14 site (0.033) at the point scale. These results beg a question because the results with the in situ measurements at the Brown site had more variations in the model performance than those at the airborne (RMSE $=0.044-0.054$ ) and satellite (RMSE $=0.060)$ scales. In situ data sets usually have a high accuracy (Ines and Mohanty, 2008a, 2008b; Shin et al., 2012), indicating that the large in situ soil moisture and/or corresponding atmospheric forcing errors in this study might be an extreme case. However, it might also show one of the potential uncertainties that can be incurred in the field. Thus, we need to explore how RS-based data can convey reliable information through different spatial scales with predictable uncertainties (i.e., atmospheric forcings, land surface variability, etc.) in applications to fields.

The estimated ET values had similar trends as the SM predictions (Fig. 9). The estimated $\mathrm{ET}$ values $(R=0.568$ and $\mathrm{RMSE}=0.784)$ matched the tower-based ET measurements, but the correlation was slightly low because of measurement errors (as shown in Fig. 9). The ET estimates $(R=0.944$ and RMSE $=1.200)$ at the airborne scale were a good match with the MODIS-based ET, but the satellite-scale ET results $(R=0.665$ and RMSE $=1.296)$ had more variations (especially DOY 129) because the AMSR-E and MODIS products have areal heterogeneity in soil texture and vegetation cover.

Based on these results, it is evident that the ET component improved the parameter estimations and contributed to the reduction in the uncertainty ranges in simulating SM and ET using inverse modeling. Although the field validation results had uncertainties, the model outputs under the SM + ET criterion matched the measurements better than the SM-only criterion under the same modeling conditions. These findings further support the robustness of the linked NMCGA and SEBAL algorithm for quantifying the effective soil hydraulic parameters at different scales under real-world conditions.

\section{Concluding Remarks}

In this study, we developed a new linked NMCGA and SEBAL based data assimilation algorithm for estimating effective soil hydraulic properties $\left(\alpha, n, \theta_{\text {res }}, \theta_{\text {sat }}\right.$, and $\left.K_{\text {sat }}\right)$ using RS SM and ET products at the point to satellite scales. Numerical experiments for the synthetic conditions and field validations were undertaken with different soil textures, climate scenarios, presence of groundwater tables, and vegetation cover under the ET-only, SM-only, and SM + ET criteria. Generally, the $\theta(b)$ and $K(b)$ functions (derived from the searched soil hydraulic parameters) under the SM + ET criterion were identified better than those of the ET-only and SM-only criteria for Case 1, although the $K(b)$ 
functions still had small variations. Because the simulated soil moisture dynamics under the $\mathrm{SM}+\mathrm{ET}$ criterion in the deeper soil depth $(180-200 \mathrm{~cm})$ for three soil textures (sandy loam, silt loam, and clay loam) had a better match with the target values than those for the ET-only and SM-only criteria, we suggest that this approach improves not only the parameter estimations but also the soil moisture dynamics (including root water uptake) in the deep soil depth (180-200 cm). In Case 2, the soil hydraulic properties in the presence of a shallow groundwater table $(-100 \mathrm{~cm})$ under the SM + ET criterion were superior to those for the SM-only criterion. It is evident that this inverse modeling based data assimilation approach including an ET component contributes towards the reduction of uncertainties generated by upward flow from the groundwater table.

In a real-world situation, the results of SM and ET estimates under the SM + ET criterion still matched the measurements from point to satellite scales better than those of the SM-only criterion as shown in the synthetic experiments (Case 1), although the correlations (the WC 12 site for SM and the WC 11 and 13 sites for ET) and RMSE (the Brown and Lubbock sites for SM) under the SM-only criterion were slightly better. At the point scale (WC 14), the SM and ET estimates identified well with the in situ soil moisture and EC ET measurements; however, the estimated SM for the Brown site had uncertainties compared with the measurements during the initial simulation period, indicating that measurement errors might cause large uncertainties in estimating the soil parameters. At the airborne scale, the SM and ET dynamics were usually estimated well at the spatial and temporal scales with uncertainties, although the discrepancy between PSR-and MODIS-based resolutions was included in the input. The satellitescale ET results have uncertainties with the SEBAL outputs, but the modeled SM estimates were comparable with the AMSR-E products. Overall, the ET estimates at the satellite scale had more variations than those at the point and airborne scales because of the limitation of the model structure, noise of pixels, heterogeneity of the land surface, etc.

The estimated soil parameters under the synthetic conditions in Cases 1 and 2 showed that our approach considerably improved the $K(b)$ functions and their uncertainties in the root zone; however, it is still not clear how individual soil parameters were correlated with SM and ET at different scales. The satellite-scale results had more variation than those at the point and airborne scales, indicating that qualities of the RS data are quite important in applications of our approach to fields. Furthermore, matching the timing of an overpass or latency period between SM (i.e., AMSR-E, Soil Moisture and Ocean Salinity [SMOS], and Soil Moisture Active Passive [SMAP]) and ET (i.e., MODIS, LANDSAT, and ASTER) as the input variables to the SEBAL or S-SEBI model) images may improve and support the performance of our proposed model better.
In this study, our findings showed that the interaction between SM and ET might contribute to better soil parameter estimations. Thus, we suggest that the linked NMCGA and SEBAL algorithm could improve soil hydraulic parameter estimations and contribute to the reduction of their uncertainties with better understanding of the water cycle in the root zone at multiple scales.

\section{Acknowledgments}

The research was funded by NASA-THP grants (NNX08AF55G, NNX09AK73G) and NSF (CMG/DMS) grants (C10-00021). We also acknowledge the assistance of Honda Kiyoshi and Khun Sand Aung of the Department of Remote Sensing and GIS, Asian Institute of Technology, for the SEBAL model used in this research.

\section{References}

Abbaspour, K.C., M.Th. van Genuchten, R. Schulin, and E. Schläppi. 1997. A sequential uncertainty domain inverse procedure for estimating subsurface flow and transport parameters. Water Resour. Res. 33:18791892. doi:10.1029/97WR01230

Allen, R.G., M. Tasumi, and R. Trezza. 2007. Satellite-based energy balance for mapping evapotranspiration with internalized calibration (METRIC): Model. J. Irrig. Drain. Eng. 133:380-394. doi:10.1061/(ASCE)07339437(2007)133:4(380)

Bastiaanssen, W.G.M., M. Menenti, R.A. Feddes, and A.A.M. Holtslag. 1998. A remote sensing surface energy balance algorithm for land (SEBAL): I. Formulation. J. Hydrol. 212-213:198-212. doi:10.1016/S00221694(98)00253-4

Bastiaanssen, W.G.M., E.J.M. Noordman, H. Pelgrum, G. Davids, B.P. Thoreson, and R.G. Allen. 2005. SEBAL model with remotely sensed data to improve water-resources management under actual field criterion. J. Irrig. Drain. Eng. 131:85-93. doi:10.1061/(ASCE)0733-9437(2005)131:1(85)

Belmans, C., J.G. Wesseling, and R.A. Feddes. 1983. Simulation of the water balance of a cropped soil: SWATRE. J. Hydrol. 63:271-286. doi:10.1016/0022-1694(83)90045-8

Beven, K., and A. Binley. 1992. The future of distributed models: Model calibration and uncertainty predictions. Hydrol. Processes 6:279-298. doi:10.1002/hyp.3360060305

Beven, K.J., and J. Freer. 2001. Equifinality, data assimilation, and uncertainty estimation in mechanistic modelling of complex environmental systems using the GLUE methodology. J. Hydrol. 249:11-29. doi:10.1016/S00221694(01)00421-8

Bindlish, R., J. Thomas, A.J. Gasiewski, M. Klein, and E.G. Njoku. 2006. Soil moisture mapping and AMSR-E validation using the PSR in SMEX02. Remote Sens. Environ. 103:127-139. doi:10.1016/j.rse.2005.02.003

Boulet, G., I. Braud, and M. Vauclin. 1997. Study of the mechanisms of evaporation under arid conditions using a detailed model of the soilatmosphere continuum: Applications to the EFEDA I experiment. J. Hydrol. 193:114-141. doi:10.1016/S0022-1694(96)03148-4

Breshears, D.D., O.B. Meyers, S.R. Johnson, C.W. Meyer, and S.N. Martens. 1997. Differential use of spatially heterogeneous soil moisture by two semiarid woody species: Pinus edulis and Juniperus monosperma. J. Ecol. 85:289-299. doi:10.2307/2960502

Cable, D. 1969. Competition in the semidesert grass-shrub type as influenced by root systems, growth habits, and soil moisture extraction. Ecology 50:27-38. doi:10.2307/1934659

Daroonwan, K., K. Honda, S. Sujittra, and S.A. Khun. 2008. Near real-time decision support system for drought monitoring and impact assessment on rice in Ubon Ratchathani, northeastern Thailand. Paper presented at the 29th Asian Conference on Remote Sensing, Colombo, Sri Lanka. 10-14 Nov. 2008.

Das, N.N., B.P. Mohanty, and E.G. Njoku. 2008. A Markov chain Monte Carlo algorithm for upscaled soil-vegetation-atmosphere-transfer modeling to evaluate satellite-based soil moisture measurements. Water Resour. Res. 44:W05416. doi:10.1029/2007WR006472

Das, N.N., B.P. Mohanty, and E.G. Njoku. 2010. Profile soil moisture across spatial scales under different hydroclimatic conditions. Soil Sci. 175:315319. doi:10.1097/SS.0b013e3181e83dd3

Droogers, P., W.G.M. Bastiaanssen, M. Beyazgül, Y. Kayam, G.W. Kite, and H. Murray-Rust. 2000. Distributed agro-hydrological modeling of an irrigation system in western Turkey. Agric. Water Manage. 43:183-202. doi:10.1016/ S0378-3774(99)00055-4

Duan, Q.Y., S. Sorooshian, and H.V. Gupta. 1992. Effective and efficient global optimization for conceptual rainfall-runoff models. Water Resour. Res. 28:1015-1031. doi:10.1029/91WR02985

Dyer, A.J. 1961. Measurements of evaporation and heat transfer in the lower atmosphere by an automatic eddy-correlation technique. Q. J. R. Meteorol. Soc. 87:401-412. doi:10.1002/qj.49708737311 
Efron, B. 1982. The jackknife, the bootstrap and other resampling plans. Soc. Ind. Appl. Math., Philadelphia, PA.

Feddes, R.A., P.J. Kowalik, and H. Zarandy. 1978. Simulation of field water use and crop yield. John Wiley \& Sons, New York.

Goldberg, D.E. 1989. Genetic algorithms in search and optimization and machine learning. Addison-Wesley Publ., New York.

Hanson, J.D., K.W. Rojas, and M.J. Schaffer. 1999. Calibrating the root zone water quality model. Agron. J. 91:171-177. doi:10.2134/agronj1999.0002 $1962009100020002 x$

Hilton, A.B.C., and T.B. Culver. 2000. Constraint handling for genetic algorithms in optimal remediation design. J. Water Resour. Plan. Manage. 126:128137. doi:10.1061/(ASCE)0733-9496(2000)126:3(128)

Holland, J.H. 1975. Adaptation in natural and artificial systems. Univ. of Michigan Press, Ann Arbor.

Huxman, T., B.P. Wilcox, D.D. Breshears, R.L. Scott, K.A. Snyder, E.E. Small, et al. 2005. Ecohydrological implications of woody plant encroachment. Ecology 86:308-319. doi:10.1890/03-0583

Ines, A.V.M., and P. Droogers. 2002a. Inverse modelling in estimating soil hydraulic functions: A genetic algorithm approach. Hydrol. Earth Syst. Sci. 6:49-65. doi:10.5194/hess-6-49-2002

Ines, A.V.M., and P. Droogers. 2002b. Inverse modeling to quantify irrigation system characteristics and operational management. Irrig. Drain. Syst. 16:233-252. doi:10.1023/A:1021231132727

Ines, A.V.M., and B.P. Mohanty. 2008a. Near-surface soil moisture assimilation for quantifying effective soil hydraulic properties using genetic algorithm: I. Conceptual modeling. Water Resour. Res. 44:W06422. doi:10.1029/2007WR005990

Ines, A.V.M., and B.P. Mohanty. 2008b. Parameter conditioning with a noisy Monte Carlo genetic algorithm for estimating effective soil hydraulic properties from space. Water Resour. Res. 44:W08441. doi:10.1029/2007WR006125

Ines, A.V.M., and B.P. Mohanty. 2009. Near-surface soil moisture assimilation for quantifying effective soil hydraulic properties using genetic algorithms: II. Using airborne remote sensing during SGP97 and SMEX02. Water Resour. Res. 45:W01408. doi:10.1029/2008WR007022

Jana, R.B., and B.P. Mohanty. 2012a. On topographic controls of soil hydraulic parameter scaling at hillslope scales. Water Resour. Res. 48:W02518. doi:10.1029/2011WR011204

Jana, R.B., and B.P. Mohanty. 2012b. A topography-based scaling algorithm for soil hydraulic parameters at hillslope scales: Field testing. Water Resour. Res. 48:W02519. doi:10.1029/2011WR011205

Jana, R.B., and B.P. Mohanty. 2012c. A comparative study of multiple approaches to soil hydraulic parameter scaling applied at the hillslope scale. Water Resour. Res. 48:W02520. doi:10.1029/2010WR010185

Jana, R.B., B.P. Mohanty, and E.P. Springer. 2007. Multiscale pedotransfer functions for soil water retention. Vadose Zone J. 6:868-878. doi:10.2136/ vzj2007.0055

Kool, J.B., and J.C. Parker. 1988. Analysis of the inverse problem for transient unsaturated flow. Water Resour. Res. 24:817-830. doi:10.1029/ WR024i006p00817

Kroes, J.G., J.C. van Dam, J. Huygen, and R.W. Vervoort. 1999. User's guide of SWAP version 2.0: Simulation of water, solute transport, and plant growth in the soil-atmosphere-plant environment. Rep. 81. DLO Winand Staring Ctr., Wageningen, the Netherlands.

Leij, F.J., W.J. Alves, M.Th. van Genuchten, and J.R. Williams. 1999. The UNSODA unsaturated soil hydraulic database. In: M.Th. van Genuchten et al., editors, Characterization and Measurement of the Hydraulic Properties of Unsaturated Porous Media: Proceedings of the International Workshop Riverside, CA. 22-24 Oct. 1997. U.S. Salinity Lab., Riverside, CA. p. 1269-1281.

Miller, B.L., and D.E. Goldberg. 1996. Optimal sampling for genetic algorithms In: C. H. Dagli et al., editors, Intelligent Engineering Systems through Artificial Neural Networks: Proceedings of the Conference, St. Louis, MO 10-13 Nov. 1996. Vol. 6. Am. Soc. Mech. Eng., New York. p. 291-298.

Mohanty, B.P., P.J. Shouse, D.A. Miller, and M.Th. van Genuchten. 2002. Soil property database: Southern Great Plains 1997 Hydrology Experiment. Water Resour. Res. 38(5). doi:10.1029/2000WR000076

Mohanty, B.P., and J. Zhu. 2007. Effective soil hydraulic parameters in horizontally and vertically heterogeneous soils for steady-state landatmosphere interaction. J. Hydrometeorol. 8:715-729. doi:10.1175/ JHM606.1

Mualem, Y. 1976. A new model for predicting the hydraulic conductivity of unsaturated porous media. Water Resour. Res. 12:513-522. doi:10.1029/ WR012i003p00513

Njoku, E. 2008. AMSR-E/Aqua daily L3 surface soil moisture, interpretive parameters, \& QC EASE-Grids V002. Natl. Snow and Ice Data Ctr., Boulder, CO.

Pachepsky, Y.A., D. Timlin, and G. Varallyay. 1996. Artificial neural networks to estimate soil water retention from easily measurable data. Soil Sci. Soc. Am. J. 60:727-773. doi:10.2136/sssaj1996.03615995006000030007x

Pollacco, J.A., and B.P. Mohanty. 2012. Uncertainties of water fluxes in soilvegetation-atmosphere transfer models: Inverting surface soil moisture and evapotranspiration retrieved from remote sensing. Vadose Zone J. 11(3). doi:10.2136/vzj2011.0167
Prueger, J., J. Hatfield, J. Albertson, T. Cahill, D. Cooper, B. Eichinger, et al. 2009. SMEX02 SMACEX tower meteorological/flux data: lowa, digital media. Natl. Snow and Ice Data Ctr, Boulder, CO.

Roerink, G.J., Z. Su, and M. Menenti. 2000. S-SEBI: A simple remote sensing algorithm to estimate the surface energy balance. Phys. Chem. Earth, Part B 25:147-157. doi:10.1016/S1464-1909(99)00128-8

Sarwar, A., W.G.M. Bastiaanssen, M.T. Boers, and J.C. van Dam. 2000. Evaluating drainage design parameters for the fourth drainage project, Pakistan by using SWAP model: I. Calibration. Irrig. Drain. Syst. 14:257-280. doi:10.1023/A:1006468905194

Schaap, M.G., and W. Bouten. 1996. Modeling water retention curves of sandy soils using neural networks. Water Resour. Res. 32(10):3033-3040. doi:10.1029/96WR02278

Schaap, M.G., and F.J. Leij. 1998. Database-related accuracy and uncertainty of pedotransfer functions. Soil Sci. 163:765-779. doi:10.1097/00010694199810000-00001

Schaap, M.G., F.J. Leij, and M.Th. van Genuchten. 1998. Neural network analysis for hierarchical prediction of soil hydraulic properties. Soil Sci. Soc. Am. J. 62:847-855. doi:10.2136/sssaj1998.03615995006200040001x

Schenk, H.J., and R.B. Jackson. 2002. Rooting depths, lateral root spreads and below-ground/above-ground allometries of plants in water-limited ecosystems. J. Ecol. 90:480-494. doi:10.1046/j.1365-2745.2002.00682.x

Sharma, S.K., B.P. Mohanty, and J. Zhu. 2006. Including topography and vegetation attributes for developing pedotransfer functions. Soil Sci. Soc. Am. J. 70:1430-1440. doi:10.2136/sssaj2005.0087

Shin, Y., B.P. Mohanty, and A.V.M. Ines. 2012. Soil hydraulic properties in onedimensional layered soil profile using layer-specific soil moisture assimilation scheme. Water Resour. Res. 48:W06529. doi:10.1029/2010WR009581

Singh, R., R.K. Jhorar, J.C. van Dam, and R.A. Feddes. 2006a. Distributed ecohydrological modelling to evaluate irrigation system performance in Sirsa district, India: II. Impact of viable water managements scenarios. J. Hydrol. 329:714-723. doi:10.1016/j.jhydrol.2006.03.016

Singh, R., J.G. Kroes, J.C. van Dam, and R.A. Feddes. 2006b. Distributed ecohydrological modelling to evaluate the performance of irrigation system in Sirsa district, India: I. Current water management and its productivity. J. Hydrol. 329:692-713. doi:10.1016/j.jhydrol.2006.03.037

Su, Z. 2002. The surface energy balance system (SEBS) for estimation of turbulent heat fluxes. Hydrol. Earth Syst. Sci. 6:85-99. doi:10.5194/hess6-85-2002

Tanner, B.D., and J.P. Greene, 1989. Measurements of sensible heat flux and water vapor fluxes using eddy correlation methods. DAAD 09-87, D-0088. Final report to U.S. Army Dugway Proving Grounds, Utah.

van Dam, J.C. 2000. Field-scale water flow and solute transport: SWAP model concepts, parameter estimation and case studies. Ph.D diss. Wageningen Univ., Wageningen, the Netherlands.

van Dam, J.C., J. Huygen, J.G. Wesseling, R.A. Feddes, P. Kabat, P.E.V. van Waslum, et al. 1997. Theory of SWAP version 2.0: Simulation of water flow and plant growth in the soil-water-atmosphere-plant environment. Tech. Doc. 45. DLO Winand Staring Ctr., Wageningen, the Netherlands.

van Genuchten, M.Th. 1980. A closed-form equation foe predicting the hydraulic conductivity of unsaturated soils. Soil Sci. Soc. Am. J. 44:892-898. doi:10.2136/sssaj1980.03615995004400050002x

van Keulen, H., and D. Hillel. 1974. A simulation study of the drying-front phenomenon. Soil Sci. 118:270-273. doi:10.1097/00010694-197410000-00008

Vrugt, J.A., H.V. Gupta, W. Bouten, and S. Sorooshian. 2003. A Shuffled Complex Evolution Metropolis algorithm for optimization and uncertainty assessment of hydrologic model parameters. Water Resour. Res. 39(8):1201 doi:10.1029/2002WR001642

Wang, Q.J. 1991. The genetic algorithm and its application to calibrating conceptual rainfall-runoff models. Water Resour. Res. 27:2467-2471. doi:10.1029/91WR01305

Wesseling, J.G., and J.G. Kroes. 1998. A global sensitivity analysis of the mode SWAP. Rep. 160. DLO Winand Staring Ctr., Wageningen, the Netherlands.

Wood, E.F. 1994. Scaling, soil moisture and evapotranspiration in runoff models. Adv. Water Resour. 17:25-34. doi:10.1016/0309-1708(94)90021-3

Wu, J., C. Zheng, C. Cien, and L. Zheng. 2006. A comparative study of Monte Carlo simple genetic algorithm and noisy genetic algorithm for costeffective sampling network design under uncertainty. Adv. Water Resour. 29:899-911. doi:10.1016/j.advwatres.2005.08.005

Xevi, E., J. Gilley, and J. Feyen. 1996. Comparative study of two crop yield simulation models. Agric. Water Manage. 30:155-173. doi:10.1016/03783774(95)01218-4

Yamanaka, T., and T. Yonetani. 1999. Dynamics of the evaporation zone in dry sandy soils. J. Hydrol. 217:135-148. doi:10.1016/S0022-1694(99)00021-9

Yeh, T.-C.J. 1989. One-dimensional steady state infiltration in heterogeneous soils. Water Resour. Res. 25:2149-2158. doi:10.1029/WR025i010p02149 